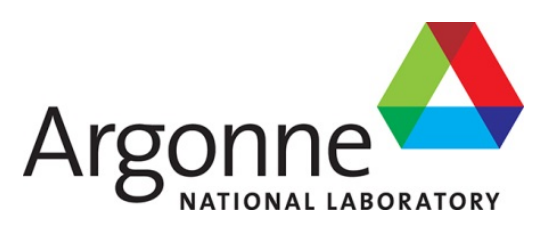

ANL/NE-17/16

\title{
Ion Mobility Spectrometer Field Test
}

Results from the former New Brunswick facility

Nuclear Engineering Division 


\begin{abstract}
About Argonne National Laboratory
Argonne is a U.S. Department of Energy laboratory managed by UChicago Argonne, LLC under contract DE-AC02-06CH11357. The Laboratory's main facility is outside Chicago, at 9700 South Cass Avenue, Argonne, Illinois 60439. For information about Argonne and its pioneering science and technology programs, see www.anl.gov.
\end{abstract}

\title{
DOCUMENT AVAILABILITY
}

Online Access: U.S. Department of Energy (DOE) reports produced after 1991 and a growing number of pre-1991 documents are available free via DOE's SciTech Connect (http://www.osti.gov/scitech/)

Reports not in digital format may be purchased by the public from the National Technical Information Service (NTIS):

U.S. Department of Commerce

National Technical Information Service

5301 Shawnee Rd

Alexandria, VA 22312

www.ntis.gov

Phone: (800) 553-NTIS (6847) or (703) 605-6000

Fax: (703) 605-6900

Email: orders@ntis.gov

Reports not in digital format are available to DOE and DOE contractors from the Office of Scientific and Technical Information (OSTI):

U.S. Department of Energy

Office of Scientific and Technical Information

P.O. Box 62

Oak Ridge, TN 37831-0062

www.osti.gov

Phone: (865) 576-8401

Fax: (865) 576-5728

Email: reports@osti.gov

\footnotetext{
Disclaimer

This report was prepared as an account of work sponsored by an agency of the United States Government. Neither the United States Government nor any agency thereof, nor UChicago Argonne, LLC, nor any of their employees or officers, makes any warranty, express or implied, or assumes any legal liability or responsibility for the accuracy, completeness, or usefulness of any information, apparatus, product, or process disclosed, or represents that its use would not infringe privately owned rights. Reference herein to any specific commercial product, process, or service by trade name, trademark, manufacturer, or otherwise, does not necessarily constitute or imply its endorsement, recommendation, or favoring by the United States Government or any agency thereof. The views and opinions of document authors expressed herein do not necessarily state or reflect those of the United States Government or any agency thereof, Argonne National Laboratory, or UChicago Argonne, LLC.
} 
ANL/NE-17/16

\section{Ion Mobility Spectrometer Field Test}

Results from the former New Brunswick facility

prepared by

Nicholas Smith, Derek McLain, Jennifer Steeb

Nuclear Engineering Division, Argonne National Laboratory

$12 / 20 / 2017$ 


\section{EXECUTIVE SUMMARY}

The Morpho Saffran Itemizer 4DX Ion Mobility Spectrometer previously used to detect uranium signatures in FY16 was used at the former New Brunswick Facility, a past uranium facility located on site at Argonne National Laboratory. This facility was chosen in an attempt to detect safeguards relevant signatures and has a history of processing uranium at various enrichments, chemical forms, and purities; various chemicals such as nitric acid, uranium fluorides, phosphates and metals are present at various levels. Several laboratories were sampled for signatures of nuclear activities around the laboratory. All of the surfaces that were surveyed were below background levels of the radioanalytical instrumentation and determined to be radiologically clean.

The results from the survey campaign indicates that the IMS spectrometer appears to be sensitive to surfaces that were exposed to uranium. A negative peak (at $~ 5.7 \mathrm{~ms}$ drift) is correlated with uranium bearing containers and adjacent surfaces. The absolute detection limit of the instrument could not be determined from this field test but the concentration range estimated at the par per million level and below traditional field radiometric techniques.

The system shows promise to conduct rapid, field checks of surfaces for not only uranium compounds but also chemicals that would be important during an inspection. These would include chemicals associated with reprocessing activities or high explosives work. This rapid chemical identification capability is not one currently available to inspectors using a commercialized detector. 


\section{CONTENTS}

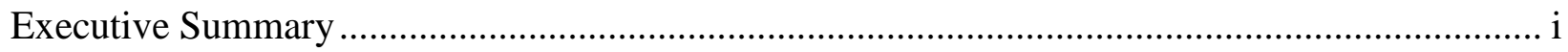

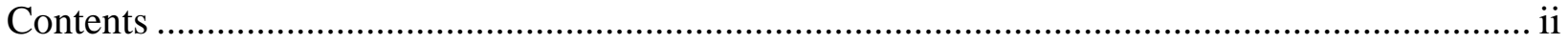

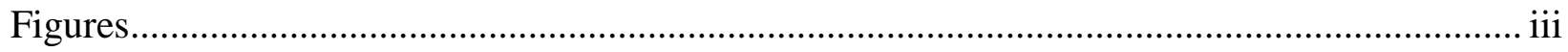

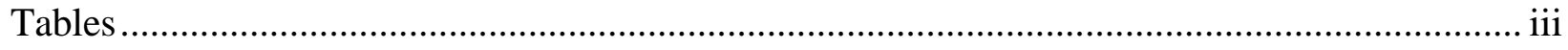

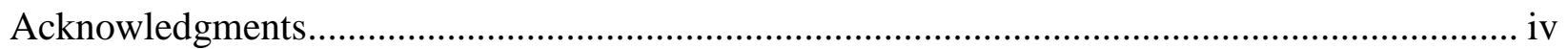

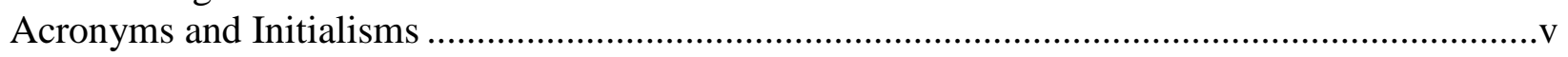

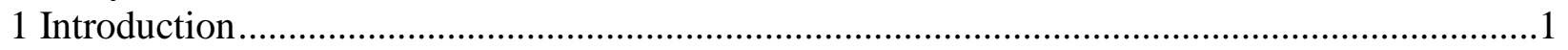

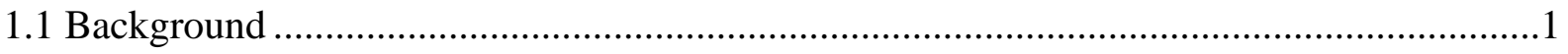

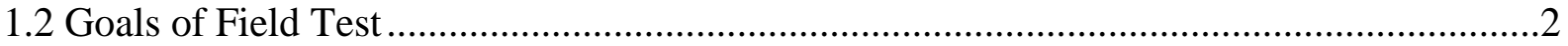

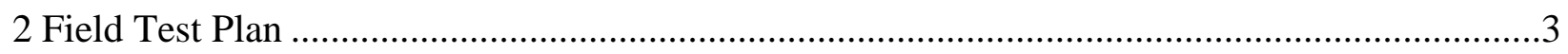

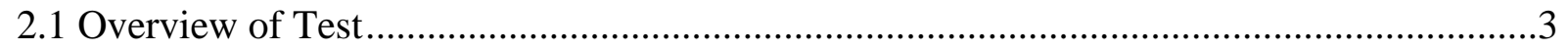

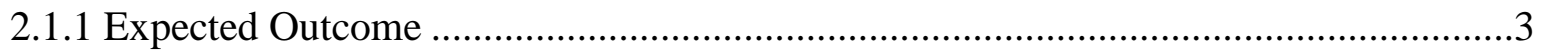

2.1.2 Test Facilities, needed Infrastructure and Equipment ............................................3

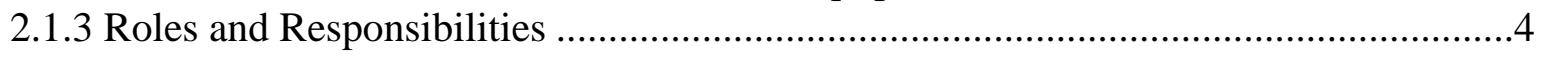

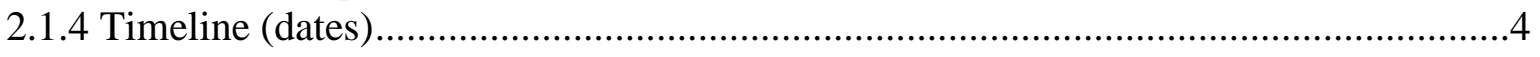

2.1.5 Data Collection.........................................................................................

2.1.6 Data Analysis and Reporting .........................................................................

2.1.7 Constraints, Risks and Mitigations (can be presented in a table or chart format)........6

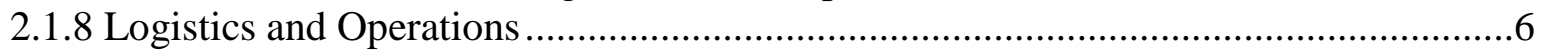

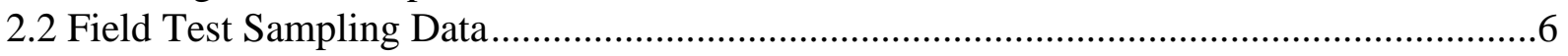

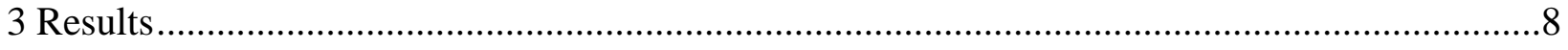

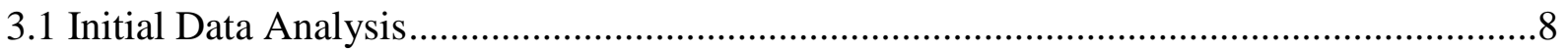

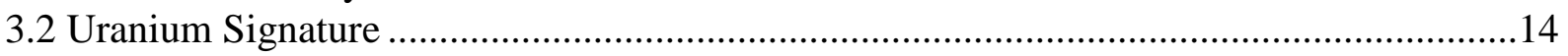

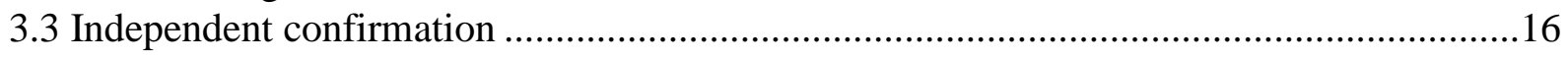

4 Conclusions, Lessons Learned and Future Work ….............................................................17

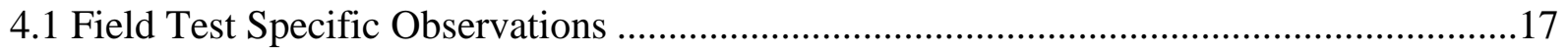

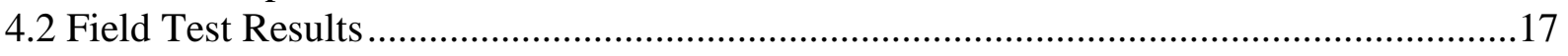

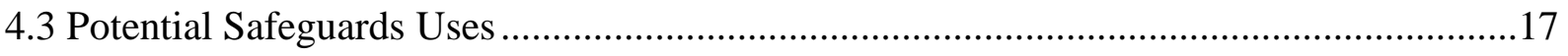

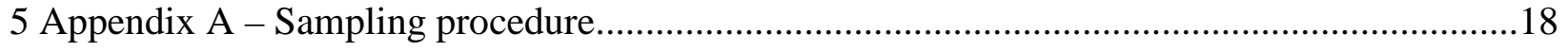

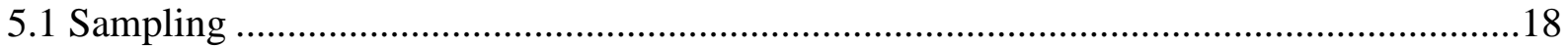

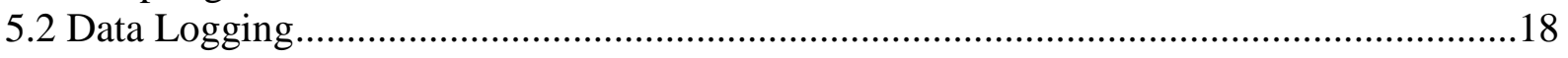

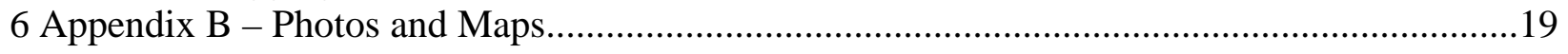




\section{FIGURES}

Figure 1 - Comparison in positive long and short modes of different uranium nitrate samples taken

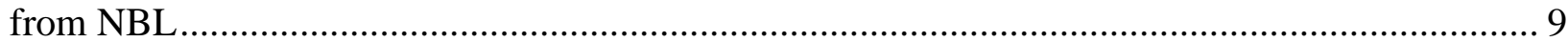

Figure 2 - Negative plasmagrams showing a likely uranium peak......................................... 10 Figure 3 - Comparison (negative long mode only) of swipes suspected of containing multiple

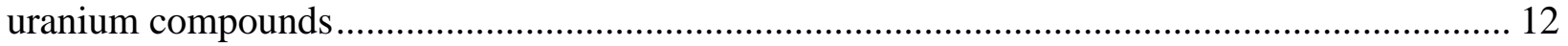
Figure 4 - Comparison in negative long mode of several non-radiological materials and areas not known to house uranium bearing materials .................................................................... 13

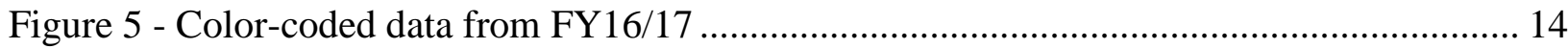

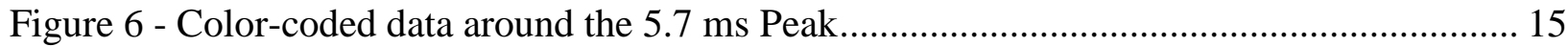

Figure 7 - Overlap of uranium and field test samples....................................................... 16

\section{TABLES}

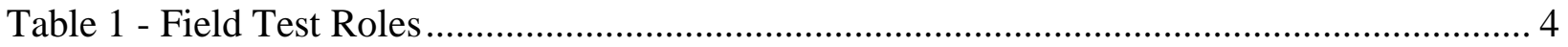

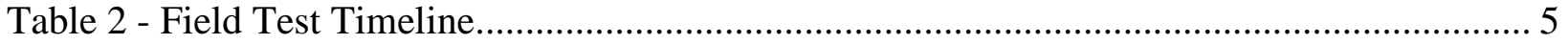

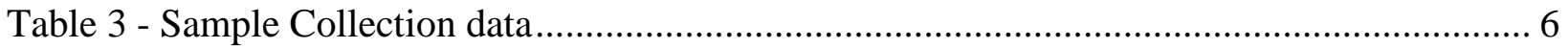




\section{ACKNOWLEDGMENTS}

The authors thank the following individuals for their support during this project:

- Bernard Christel, Stacy Sternberg, and Michael Grimes for their support of operations in Bldg. 350 


\section{ACRONYMS AND INITIALISMS}

ANL

Argonne National Laboratory

CA Complementary Access (Inspection)

COTS ..Commercial Off The Shelf

CSV Comma Separated Value DHS. of Homeland Security
Department of Energy

DOE

EV ID ..Health Physics
Air Conditioning HP

HVAC Heating, Ventilation, Air Conditioning

IMS ..Ion Mobility Spectrometry

MCA Material Control and Accountability NBL New Brunswick Laboratory

PI Principal Investigator

PPE . Personal Protective Equipment

WCD .Work Control Document 


\section{INTRODUCTION}

This project aims to demonstrate the ability of a Commercial Off-The-Shelf (COTS) Ion Mobility Spectrometer (IMS) system to operate in the field for nuclear fuel cycle-based samples. The system can rapidly determine the chemical form of radioactive and nonradioactive compounds; this ability would be a useful addition to the inspector toolkit. This project was previously funded at the exploratory level in FY16 to demonstrate proof of concept to detect radiological chemical compounds of interest. The Argonne team has expertise in hard and soft ionization mass spectrometry research, specifically with ion mobility and electrospray ionization mass spectrometry measurements. Argonne also has experience working with instrument manufacturers to expand or alter proprietary software to add functionality.

The IMS was able to detect and discriminate between a number of chemical signatures in FY16, including uranium hexafluoride, uranyl fluoride, uranium tetrafluoride, various uranium oxides, nitric acid and tri-n-butyl phosphate in dodecane. The ability of the instrument to detect these compounds in a realistic environment would be an asset for both INFCIRC-153 and INFCIRC-540 inspection activities. Indeed, IMS systems are already deployed for the purpose of chemical weapons monitoring

If successful, IMS systems can be used to assess an area rapidly during an inspection to identify areas for follow-on analyses such as destructive analysis via Environmental Swipe Samples. In addition, the IMS can provide chemical information on non-nuclear species that may be of interest as well as residues of high explosives or other energetic compounds. The systems are man portable and relatively inexpensive for the utility they provide for in-field analysis.

\subsection{BACKGROUND}

Ion Mobility Spectrometry is an analytical technique that allows for rapid chemical identification of volatile and semi-volatile chemical compounds. The technique is based upon differentiating chemical compounds by differences in the mobility of the ions formed during an ionization process. The ions formed are allowed to drift down a tube filled with carrier gas ions that is biased by an electric field, and the time required for the ion to traverse the length of the tube is recorded. Likewise, the ion mobility spectrometer can detect positive and negative ions based upon the polarity of the bias applied to the drift tube, allowing for recording of all mobility times of charged ions. Both modes can be further divided into short and long modes, which can be used to make fine distinctions in chemical species; for the purposes of this study, we will be focused on the positive and negative short results.

An Itemiser 4DX IMS instrument with a $\mathrm{Kr}$ ionization lamp from Morpho Detection (Newark, CA) was used for the analysis of all samples. Variations of portable ion mobility spectrometers are used to screen for explosives on the extremities and personal belongings of fliers that board an aircraft within the United States. A smear is taken and placed within the IMS where the compounds on the smear are heated, volatilized into the instrument, measured, and compared against a signature database of spectra for explosives and harmful chemicals within approximately 10 seconds. Ion mobility spectrometers have been in use for several decades for identification of chemical compounds, and have been available as commercial-offthe-shelf, portable equipment for over 20 years. 
In this work, each sample was acquired on a Morpho Detection high-performance collection sample trap. If the sample was suspected of containing radioactive material, it was analyzed for alpha and beta radiation on an alpha/beta proportional counter prior to IMS analysis to determine if there was a risk for internally contaminating the instrument. If a measurable amount of radioactive material was present, the sample was counted again after IMS analysis so the potential internal contamination level was known. For every sample, the IMS instrument generated four different spectra: positive ion detection with a long drift time and a short drift time (hereafter referred to as positive long and positive short, respectively), and negative ion detection with a long drift time and a short drift time (hereafter negative long and negative short, respectively). The exact drift times for the short and long analyses are proprietary to the instrument manufacturer. The compounds analyzed could produce signatures in negative ion mode, positive ion mode, or both depending on the breakdown products' affinities for positive and negative charges.

During the FY16 scoping study, the IMS was able to detect and differentiate between radioactive and nonradioactive compounds of interest to the safeguards community. The higher the volatility (and lower vapor pressure) of each compound tested, the more pronounced differentiation between spectra was produced. The IMS was able to differentiate between molecular iodine and iodate salts, sodium salts with different anions, and major differences between uranyl nitrate, uranium hexafluoride, and uranium oxide. Since this instrument does not have a mass spectrometer as its COTS configuration, the final spectra could not be analyzed to pinpoint chemical speciation; however, highly reproducible results were achieved that could be correlated with specific chemicals.

\subsection{GOALS OF FIELD TEST}

The goal of this test was to determine if the IMS sampler could be used to identify nuclear materials (uranium compounds) in a realistic environment. Samples were taken in situ in the former New Brunswick Laboratory building (building 350). Instrument response levels were compared to traditional health physics observations.

One of the major concerns is overlapping signatures. While studies in FY16 used pure compounds, the ability to resolve multiple components is uncertain. Therefore, testing with at least two compounds present is required. Also, testing with a wide variety of material types (solids, solution residues, chlorides, etc.) is required to ensure that mixed chemical forms can be resolved.

The IMS must be able to compete with traditional methods of analysis to justify the use of the instrument. While the instrument may not be able to match International Target Values (ITVs) for uncertainty in uranium detection, the system can provide real time feedback on chemical compounds present in a facility. This ability can augment the analysis of that facility and allow more complete safeguards conclusions to be drawn on that facility. Therefore, to add value, the IMS must be able to detect materials of interest in a facility. 


\section{FIELD TEST PLAN}

This test provided several material types and associated compounds for identification of uranium in a realistic environment. Many of the signals that were examined during FY16 laboratory tests will be present in the field test environment. The objective is to detect materials when there are multiple IMS-responsive chemicals present.

\subsection{OVERVIEW OF TEST}

The IMS unit was transported to building 350 on the Argonne campus. The unit was then used to collect samples under the guidance of the local health physics contingent. The HP technicians directed the field test team to areas that have either known contamination or where operations occurred in the past. The former was used for a positive test while the latter was used as a means to resemble real field use. Multiple samples were collected and analyzed over the course of the test.

\subsubsection{EXPECTED OUTCOME}

The realistic performance of the instrument to detect compounds in a non-ideal environment was the main goal of the field test. Especially in positive test locations (areas with known contamination), it is important to observe that the instrument provides a usable data stream in the presence of, possibly multiple, impurities. International inspection agencies are the intended customer as the IMS can identify chemical components as well as radiological components that may have safeguards and complementary access (CA) inspection importance. No capability currently exists to identify chemicals in the field. Two usage modes are envisioned: 1) prescreening locations during a verification inspection to identify areas where Environmental Swipe Samples should be taken or 2) detecting chemicals associated with reprocessing in real time in the field during a verification or CA inspection.

The field test host facility is actively undergoing de-inventory and decontamination activities and will likely gain nothing from this experience; the field test will likely be transparent to ongoing operations.

\subsubsection{TEST FACILITIES, NEEDED INFRASTRUCTURE AND EQUIPMENT}

This test occurred at the former New Brunswick Laboratory facility recently transferred to Argonne ownership. The facility is currently operating as an Argonne building with full power, light, water, potable water, HVAC and other services. Other than physical access to the facility, access to those services above, and health physics support (below), no additional infrastructure support or equipment was required. Health Physics support included a technician on hand for the entire field test to count (via an $\alpha / \beta$ proportional counter) all IMS Sample traps prior to and after analysis by the IMS. This was required to track the amount of material that is contained within the IMS as well as to give a rough estimate of the amount of material on the sample prior to analysis by IMS 


\subsubsection{ROLES AND RESPONSIBILITIES}

Table 1 - Field Test Roles

\begin{tabular}{|c|c|c|c|}
\hline Role & Responsibility & $P O C$ & Organization \\
\hline Program Manager & Test Plan Approval & Arden Dougan & DOE NA-241 \\
\hline Test Director & Plan test and logistics & Nicholas Smith & ANL \\
\hline IMS PI & $\begin{array}{l}\text { Provide technical } \\
\text { advice and data } \\
\text { analysis }\end{array}$ & Jennifer Steeb & ANL \\
\hline $\begin{array}{l}\text { Field test building } \\
\text { manager }\end{array}$ & $\begin{array}{l}\text { Coordinates access to } \\
\text { building and } \\
\text { personnel }\end{array}$ & Bernard Christel & ANL \\
\hline $\begin{array}{l}\text { Health Physics } \\
\text { support (building } \\
\text { 350) }\end{array}$ & $\begin{array}{l}\text { Provides access to } \\
\text { health physics } \\
\text { technicians }\end{array}$ & Stacy Sternberg & ANL \\
\hline MCA Escort & $\begin{array}{l}\text { Allows access to } \\
\text { building } 350 \text { Material } \\
\text { Control Areas }\end{array}$ & $\begin{array}{l}\text { Bernard Christel } \\
\text { (primary); Manjula } \\
\text { Pfingston (alternate) }\end{array}$ & ANL \\
\hline
\end{tabular}

\subsubsection{TIMELINE (DATES)}

A test agreement with the host facility was not needed as the Field Test occurred after the handoff of building 350 from the NBL Project Office to the Argonne Site Office (completed for April, 2017). The test plan approval was granted through the use of local work planning and control and radiation protection systems at Argonne to control all hazards and provide mitigations (see appendix). All Safety approvals were granted in the appropriate work authorization business systems in late July.

The field test was scheduled for August 7-11 with a backup date range of the week of August 21; the original dates of testing were kept. The instrument was moved to Building 350 and calibrated on the first day of the field test. The entire collection portion occupied the remainder of the week with sample analysis continuing into Friday. The sequence of events are as follows: the researchers entered the facility with HP support and proceeded to collect as many different samples as possible during the course of the day (see Appendix A for sampling procedure). Samples were collected from three different areas within the field test laboratories: direct collections from uranium certified reference material containers (exterior only); adjacent to uranium preparation areas; and areas in the laboratory that should have no direct uranium contributions. Pictures and metadata were collected for each sample. The instrument remained at Bldg. 350 until testing was completed.

The instrument was surveyed and released from Bldg. 350 and transported back to Bldg. 205 after the field test. The IMS provides on-screen feedback immediately upon 
completion of a scan; if results are obtained from areas where either no materials are expected or if a sample otherwise alarms or provides low-fidelity data, replacement samples can be taken immediately.

Table 2 - Field Test Timeline

\begin{tabular}{|c|c|c|}
\hline August 7 & August 8-10 & August 11 \\
\hline $\begin{array}{l}\text { - Transport IMS to } 350 \text {. } \\
\text { Calibrate and check function. } \\
\text { - Prepare HP support } \\
\text { equipment }\end{array}$ & $\begin{array}{l}\text { - Resolve any } \\
\text { calibration issues } \\
\text { with IMS. } \\
\text { - Start Data Collection } \\
\end{array}$ & $\begin{array}{l}\text { - Finalize collections; otherwise } \\
\text { prepare instrument for transport to } \\
205 .\end{array}$ \\
\hline $\begin{array}{l}\text { - } 0900 \text { : Pickup GOV vehicle } \\
\text { and transport IMS from } \\
\text { B205 } \\
\text { - } 1030 \text { : Setup IMS } \\
\text { - 1200: Lunch } \\
\text { - 1300: IMS Calibrations } \\
\text { - } 1430 \text { : Catalog and setup } \\
\text { materials for collections } \\
\text { - } 1700 \text { : End (earlier as needed) }\end{array}$ & $\begin{array}{l}\text { - } 0900: \text { Start } \\
\text { collections } \\
\text { - } 1200: \text { Lunch } \\
\text { - } 1300: \text { Continue } \\
\text { collection } \\
\text { - } 1700: \text { End }\end{array}$ & $\begin{array}{l}\text { - 0900: Determine internal } \\
\text { contamination with HP; package any } \\
\text { swipes for external measurement. } \\
\text { - 1100: package and mark IMS for } \\
\text { shipment. Contact MCA if needed. } \\
\text { - 1200: Lunch } \\
\text { - 1300: Transport or arrange transport } \\
\text { - 1400: Cleanup (as needed) } \\
\text { - 1700: End }\end{array}$ \\
\hline - Personnel: & - Personnel: & - Personnel: \\
\hline $\begin{array}{l}\text { o Nicholas Smith, Derek } \\
\text { McLain }\end{array}$ & $\begin{array}{l}\text { Nicholas Smith, } \\
\text { Derek McLain }\end{array}$ & $\begin{array}{ll}\text { o } & \text { Nicholas Smith, Derek McLain } \\
\text { o } & \text { HP Technician }\end{array}$ \\
\hline o HP Technician & o HP Technician & o MCA Escort \\
\hline o MCA Escort & o MCA Escort & \\
\hline
\end{tabular}

\subsubsection{DATA COLLECTION}

All electronic IMS data was collected on the instrument and the sample identification was logged electronically. Pictures of each sampling location was taken with an identifying marker. Any information on the materials present in the area of the scan was collected, such as identities of materials in the area, Certificates of Analysis, etc. Additional swipes will be collected in the sampling area for possible outside analysis to provide a ground truth measurement of the IMS sample.

All IMS output scans were tabulated and placed in CSV file format to facilitate data manipulation and interpretation. Information regarding starting and ending uranium activity (via HP measurements) were logged to determine total possible internal uranium contamination of the IMS.

\subsubsection{DATA ANAL YSIS AND REPORTING}

Data analysis consisted of examining the collected spectral data for correlations against known samples. Currently, IMS data for non-calibrated species is qualitative and requires an analyst to interpret the collected data. Jennifer Steeb leadled the data analysis segment.

All raw and processed data will be the property of Argonne National Laboratory and will be distributed to NA-241 as needed. All reports will be processed for official release through the PANDA system at Argonne and will be distributed to OSTI unless protected by applicable restrictions. 


\subsubsection{CONSTRAINTS, RISKS AND MITIGATIONS (}

No real risks were present save for the complete closure of the facility to all work. There was no indication that this is a real or predictable outcome at this point. The schedule for this operation was very flexible within the month of August.

\subsubsection{LOGISTICS AND OPERATIONS}

All safety, PPE, and training was managed through the Argonne Training Management System as defined by the WCD. All materials were returned to Bldg. 205. The required presence of a building 350 MC\&A and HP representatives, as work cannot be performed without these individuals, was a known scheduling hazard. This was mitigated by scheduling both resources $>30$ days prior to the first testing window.

\subsection{Field Test SAmpling Data}

The samples in Table 1 were collected in the Bldg. 350 Uranium Wing in several laboratories. The single sample collected in series one was taken to ensure the instrument had been set up properly and would work after being moved to building 350. Each sample in series 2 was photographed and logged on a laboratory map (See Appendix B - Photos and Maps); samples in series 3 were logged on the laboratory maps and group shots were taken for 3-001 through 3-011. If an external verification swipe sample was taken in the same location, the specific EV ID is logged.

Table 3 - Sample Collection data. See Appendix B for visual indications

\begin{tabular}{l|clcc}
\hline Room & $\begin{array}{c}\text { Sample } \\
I D\end{array}$ & $\begin{array}{l}\text { Metadata (chemical, enrichment level, etc.) } \\
\text { from sample area }\end{array}$ & $\begin{array}{c}\text { EV } \\
\text { ID }\end{array}$ & $\begin{array}{c}\text { IMS Alarms } \\
\text { (Explosives/Narcotics) }\end{array}$ \\
& & & \\
\hline C110 & $1-001$ & Computer desk near MAT261 & & \\
C110 & $2-001$ & Calibration Check & & \\
C110 & $2-002$ & Logbook & & \\
C110 & $2-003$ & Flammable Cabinet & & \\
C110 & $2-004$ & Countertop near pyrometer & E5 \\
C110 & $2-005$ & Counter near filament wheel & & E5 \\
C110 & $2-006$ & Floor near waste bin & & E4 \\
C110 & $2-007$ & MAT261 port & P3 & E1, E4,E5 \\
C110 & $2-008$ & Counter under cabinet & & E5, E1-2/9 \\
C110 & $2-009$ & Counter in front of drying oven & & E1-2/E9 \\
C126 & $2-010$ & Exterior (top) of CRM 111-A containers & P4 & E5,E9/E1, E1-2/E9 \\
C126 & $2-011$ & EU solutions tray, exterior counter & P5 & E5,E5, E1-2/E9 \\
C126 & $2-012$ & EU solution tray, lip & P6 & E5, E5 \\
C126 & $2-013$ & Cabinet shelf near dried U residues in beakers & P6 & E1, E5 \\
C126 & $2-014$ & Near balance & & E4, E1-2/E9 \\
C126 & $2-015$ & Fume hood lip & P9 & E2/E3 \\
C126 & $2-016$ & Benchtop near sink & P10 & E1/E5 \\
\hline
\end{tabular}




\begin{tabular}{|c|c|c|c|c|}
\hline Room & $\begin{array}{c}\text { Sample } \\
\text { ID } \\
\text { (Day- } \\
\text { \#\#\#) }\end{array}$ & $\begin{array}{l}\text { Metadata (chemical, enrichment level, etc.) } \\
\text { from sample area }\end{array}$ & $\begin{array}{l}E V \\
I D\end{array}$ & $\begin{array}{c}\text { IMS Alarms } \\
\text { (Explosives/Narcotics) }\end{array}$ \\
\hline C126 & $2-017$ & Upper benchtop, island & P10 & E5, E1-2/E9 \\
\hline C126 & $2-018$ & $\begin{array}{l}\text { Benchtop near desiccator containing loose } \\
\text { uranium samples }\end{array}$ & P10 & $\mathrm{E} 1, \mathrm{E} 5$ \\
\hline C126 & 2-019 & Floor under work areas & & \\
\hline C138 & $2-020$ & U Phosphoric acid sample tray & & \\
\hline C138 & $2-021$ & Shelf near aluminum block & P13 & $\mathrm{E} 1, \mathrm{E} 5, \mathrm{~N} 1$ \\
\hline C138 & $2-022$ & Top of furnace & $\mathrm{p} 14$ & \\
\hline C138 & $2-023$ & Bench near balance & $\mathrm{p} 16$ & \\
\hline C138 & $2-024$ & Hood lip & & \\
\hline C138 & $2-025$ & Bench near brass canister & & \\
\hline C138 & $2-026$ & $\begin{array}{l}\text { Shelf near uranium nitric acid samples } \\
\text { (O8QU0193) }\end{array}$ & p15 & E5, E1-2/E9, N1, N6 \\
\hline C138 & $2-027$ & $\begin{array}{l}\text { Shelf near uranium nitric acid samples } \\
(12 \mathrm{Q} 0002 \mathrm{~K})\end{array}$ & p15 & \\
\hline C138 & $2-028$ & Bench near gas lines & $\mathrm{p} 16$ & \\
\hline C138 & $2-029$ & Sink & & \\
\hline C126 & $3-001$ & Uranyl Nitrate bottle 02EU0074 & P5/6 & E2/E3 \\
\hline C126 & $3-002$ & Uranyl Nitrate bottle 03EU0038 & P5/6 & E2/E3 \\
\hline C126 & $3-003$ & Uranyl Nitrate bottle 93\% 116 & P7 & \\
\hline C126 & $3-004$ & Uranyl Nitrate bottle NFU02-00002 & P7 & E2/E3 \\
\hline C126 & $3-005$ & Uranyl Nitrate bottle 12EU0070-09 & P7 & \\
\hline C126 & $3-006$ & Uranyl Nitrate bottle 12EU0070_02 & P7 & E2/E3 \\
\hline C126 & $3-007$ & Uranium solids & P8 & E2/E3 \\
\hline C126 & $3-008$ & Uranium oxides & P8 & E2/E3 \\
\hline C138 & $3-009$ & Uranyl Nitrate solids 08gu0001 & $\mathrm{p} 13$ & E1, E5 \\
\hline C138 & $3-010$ & Uranyl Phosphate bottle c112a & P16 & E5 \\
\hline C138 & $3-011$ & Uranium metal 97Nu0101 & & \\
\hline C126 & $3-012$ & Desiccator with $\mathrm{UF}_{4}{ }^{*}$ & & $\mathrm{E} 2 / \mathrm{E} 3, \mathrm{~N} 1$ \\
\hline $\mathrm{C} 250$ & $3-013$ & Furnace* & $\mathrm{p} 19$ & \\
\hline C238 & $3-014$ & Benchtop* & p17 & $\begin{array}{c}\text { E2/E3, E9/E1,E1-2/E9, } \\
\text { N1 }\end{array}$ \\
\hline
\end{tabular}




\section{RESULTS}

Based on preliminary results from FY16 (and using the spectra from that campaign for comparison/standard data), an analysis was performed of the IMS data from the NBL facility. To generate the data shown below, the IMS software examines the signals collected over time, determines signals in a temporal domain, and generates a plasmagram of the sample. Each plasmagram is a collection of data points where the abscissa is determined by drift time and the ordinate is an intensity provided by a proprietary algorithm (likely proportional to total signal). These data points were exported from the spectrometer and displayed as scatterplot points in Excel. To facilitate comparison, a vertical line was dropped from each data point. The points may be color-coded depending on the analysis. Each plasmagram generally has multiple peaks, likely due to contamination of the sample traps by environmental factors. However, identification for most items in the on-board library (narcotics and explosives) are tied to a single diagnostic peak/peak shape. Therefore, consistent matching of a single peak across multiple samples with similar chemistry would be considered a "positive" result and will be reported.

\subsection{Initial Data Analysis}

Compared against several blanks, uranyl phosphate and uranyl nitrate both exhibit distinct peaks in the positive long and positive short end of the spectrum, at approximately 6.2 ms drift time (Figure 1). Since three separate blanks did not have any peaks at this location, this would be an initial indication that a peak at $6.2 \mathrm{~ms}$ may be unique to uranium compounds. Additionally, it is important to note that none of the uranium smears were found to be above background during radiometric analysis. This would indicate the IMS instrument may be able to detect the presence of uranium at lower levels than routine radio analytical measurements.

The set of spectra displayed in Figure 2 are representative of efforts to find peaks that could definitively identify uranium. Several swipes that A) were known to have uranium (i.e., 14 Uranyl Nitrate Swipe 1) or B) were taken in areas where it was highly likely to be found (e.g., 3-002 Uranyl Nitrate Bottle) were analyzed. All of the uranium bearing samples shared a peak at $\sim 5.7 \mathrm{~ms}$ in the negative short plasmagram that is not shared with bulk nitric acid. This is in addition to the previously identified $6.2 \mathrm{~ms}$ peak in the positive long/short spectra shown in Figure 1. No peak was found that corresponded to both uranyl nitrate and nitric acid. Due to all swipes being below background levels, is it encouraging that this method may be able to consistently detect uranium at levels below radiological background measurements 


\section{Positive Long}

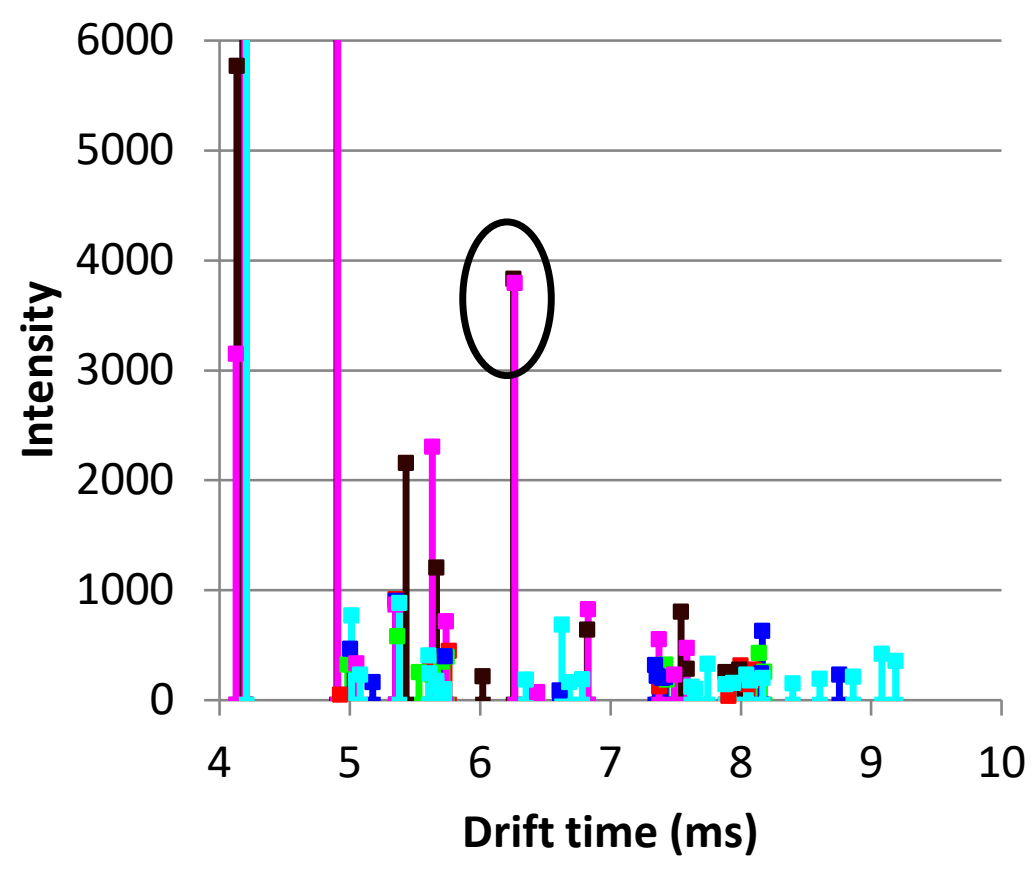

— 2016100601 Paper Blank.sca

2016100603 paper blank.sca

— 2016100607 paper blank.sca

• 3-010 Uranyl Phosphate bottle c112a

3-009 Uranyl Nitrate solids 08gu0001

2-003 Flammable Cabinet

\section{Positive Short}

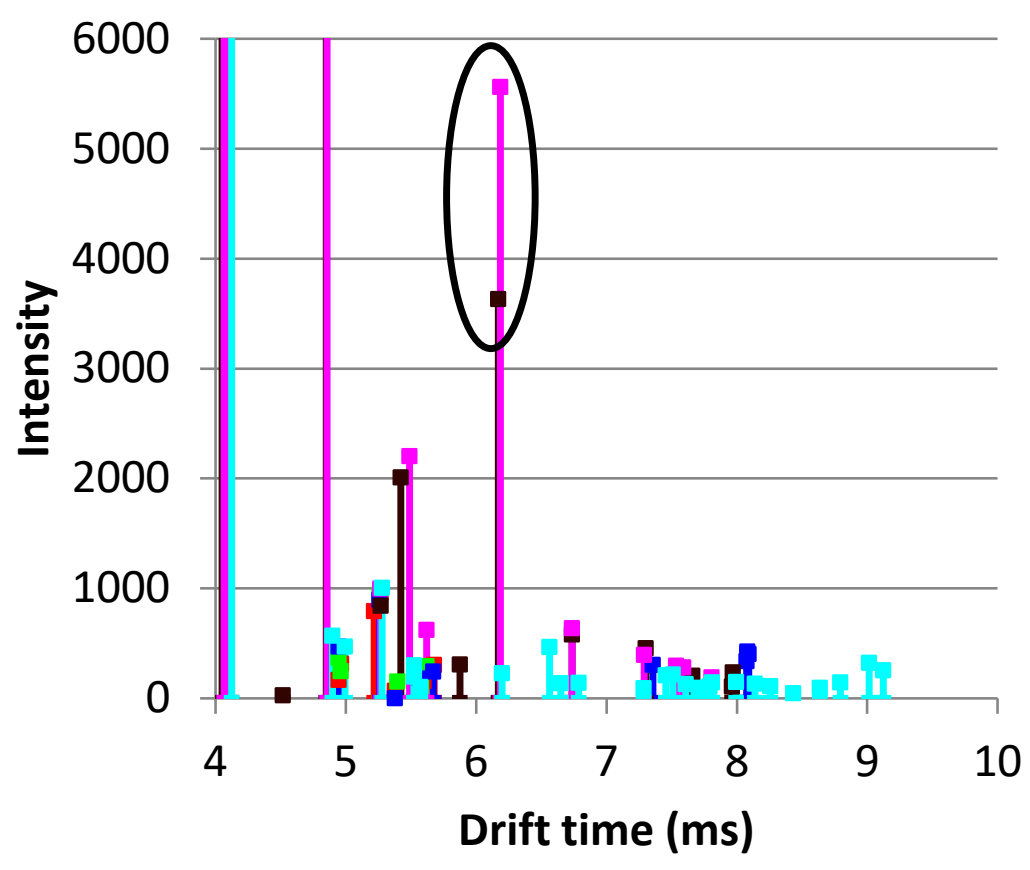

— 2016100601 Paper Blank.sca

2016100603 paper blank.sca

— 2016100607 paper blank.sca

- 3-010 Uranyl Phosphate bottle c112a

-3-009 Uranyl Nitrate solids 08gu0001

2-003 Flammable Cabinet

Figure 1 - Comparison in positive long and short modes of different uranium nitrate samples taken from NBL. 


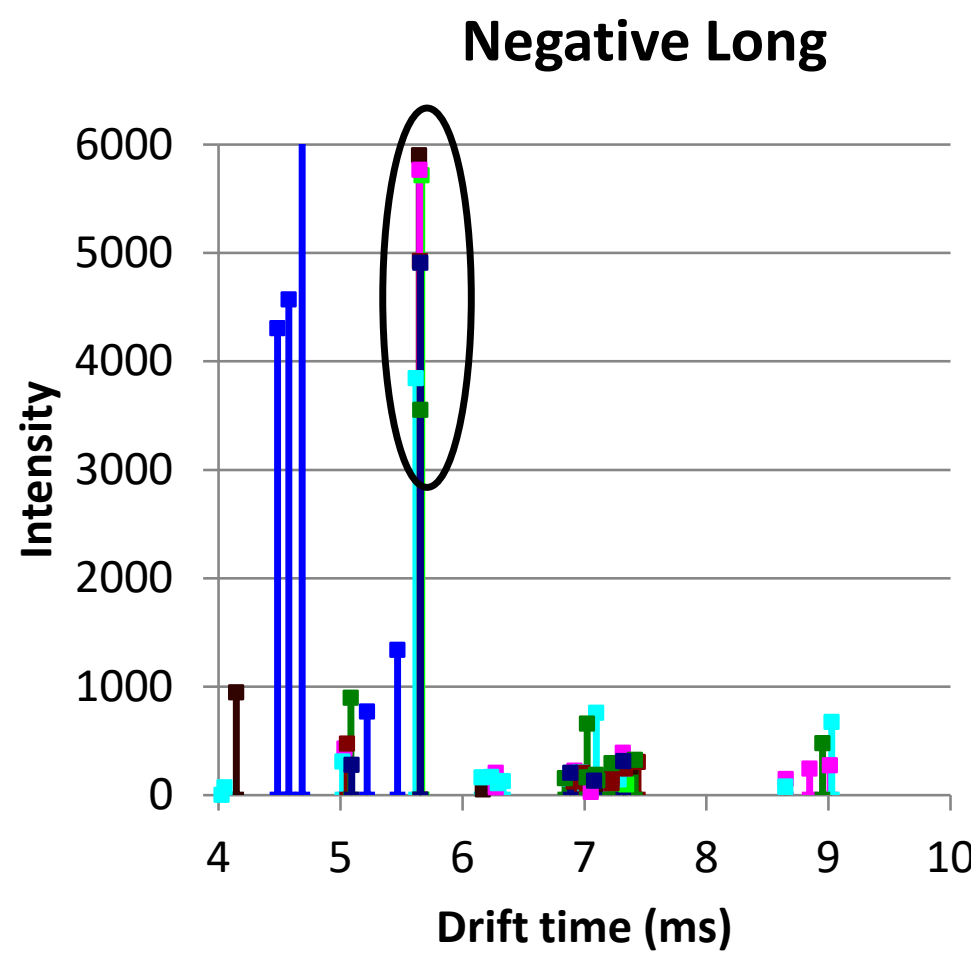

[ 2016100601 Paper Blank.sca

14 Uranyl nitrate swipe 1

2016101210 nitric acid bottle (alm00027.sca)

• 3-001 Uranyl Nitrate bottle 02EU0074

3-002 Uranyl Nitrate bottle 03EU0038

3-003 Uranyl Nitrate bottle 93\% 116

• 3-004 Uranyl Nitrate bottle NFU02-00002

3-005 Uranyl Nitrate bottle 12EU0070-09

• 3-006 Uranyl Nitrate bottle 12EU0070_02

Negative Short

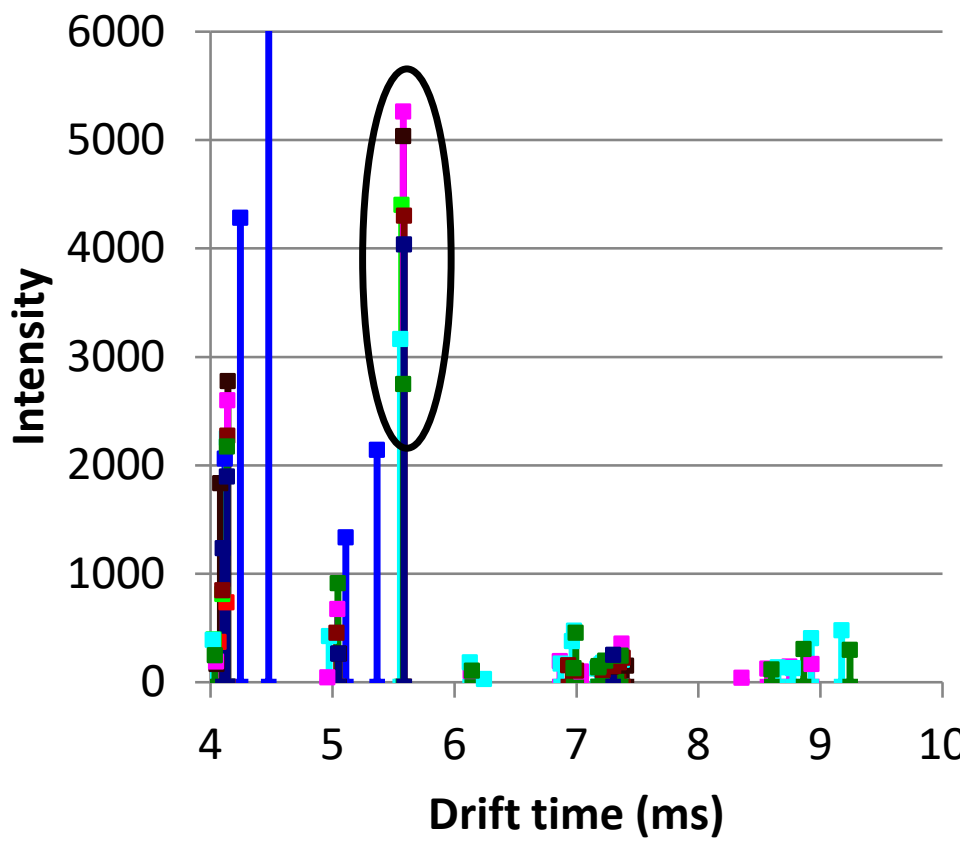

— 2016100601 Paper Blank.sca

14 Uranyl nitrate swipe 1

- 2016101210 nitric acid bottle (alm00027.sca)

• 3-001 Uranyl Nitrate bottle 02EU0074

• 3-002 Uranyl Nitrate bottle 03EU0038

3-003 Uranyl Nitrate bottle 93\% 116

• 3-004 Uranyl Nitrate bottle NFU02-00002

• 3-005 Uranyl Nitrate bottle 12EU0070-09

—3-006 Uranyl Nitrate bottle 12EU0070_02

Figure 2 - Negative plasmagrams showing a likely uranium peak. 
In Figure 3, different types of uranyl compounds and areas suspected of containing uranyl compounds (like uranyl fluoride and uranyl phosphate) were swiped and compared against the uranyl nitrate solids compound (only Negative Long shown). Surprisingly, all uranyl compounds presented in these figures had both the $5.7 \mathrm{~ms}$ drift time negative long and negative short peak, and the $6.2 \mathrm{~ms}$ drift time positive long and positive short peak.

Several explanations could explain these findings. First, it is possible that the IMS is unable to distinguish between different types of uranyl salt species, and these peaks are only indicative of a positive uranium compound with no regard for the anion. Second, there may only be a positive uranyl and negative uranyl species and no anionic species from the salt that can be directly measured (nitrate, phosphate, fluoride, etc.). Third, the weights of nitrate and phosphate are close in mass (m/z 62 nitrate, $\mathrm{m} / \mathrm{z} 80$ phosphate); it is possible that phosphate could be dissociating to $\mathrm{PO}_{3}{ }^{2-}$ within the IMS chamber, that would effectively be the same mass as nitrate (m/z 64 vs. $\mathrm{m} / \mathrm{z}$ 62) though this does not account for the oxide and metal samples. Additionally, the uranyl fluoride samples matches both the negative and positive mode peaks shown for the other uranyl compounds. This includes both a swipe of a desiccator that was known to contain $\mathrm{UF}_{4}$ at some point in its lifetime as well as a direct sample of $\mathrm{UF}_{4}$. The species could have easily decayed or nitrates could have actually been present, attributing to the positive match, though that is far from certain. Since the species we swiped were all below detection limits, it would be very difficult to use any other type of analytical instrumentation to confirm nitrates or phosphates on the smear. Given these results, it is reasonable to assume that the $6.2 \mathrm{~ms}$ positive and $5.7 \mathrm{~ms}$ negative peaks are attributable to uranium and not to the various anions.

In Figure 4, swipes of areas adjacent to uranyl species were measured. Only in Figure 4, with the logbook and the flammable cabinet, was a single $5.7 \mathrm{~ms}$ drift peak observed in the negative long and negative short mode. The 6.2 peak in positive long and positive short mode was not observed in any other compound, which is strong evidence that the $5.7 \mathrm{~ms}$ and $6.2 \mathrm{~ms}$ drift peaks positively identify uranium. Although during this blind test of NBL we were unable to definitively identify differences in uranyl salts, this is not to say the tests at NBL were not successful. Several uranyl samples matched the same two identification peaks in several figures, reassuring us that this method can distinguish lower concentrations of uranium compounds from background than possible with field radiological determinations in facilities. For the future, we would have to determine the IMS signal associated with uranium naturally present in soil and dust (ppm levels) to prevent false positives if the instrument is employed as envisioned. 


\section{Negative Long}

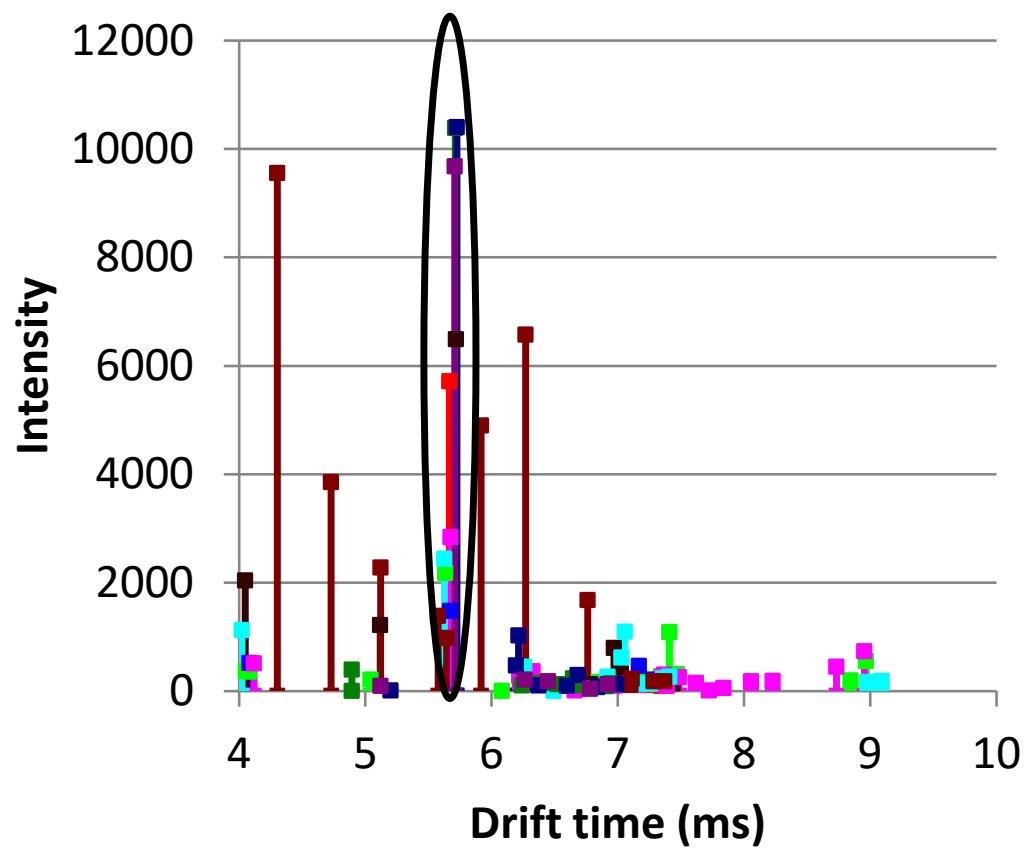

14 Uranyl nitrate swipe 1

3-011 uranium metal 97Nu0101

• 3-010 Uranyl Phosphate bottle c112a

- 3-012 Dessicator with UF4

-2-020 U Phosphoric acid sample tray

3-009 Uranyl Nitrate solids 08gu0001

— 2016101902 UF6

— 2016102602 U308

— 2016102601 UF4

— 2016102603 U METAL RECTANGLE

\section{Negative Long}

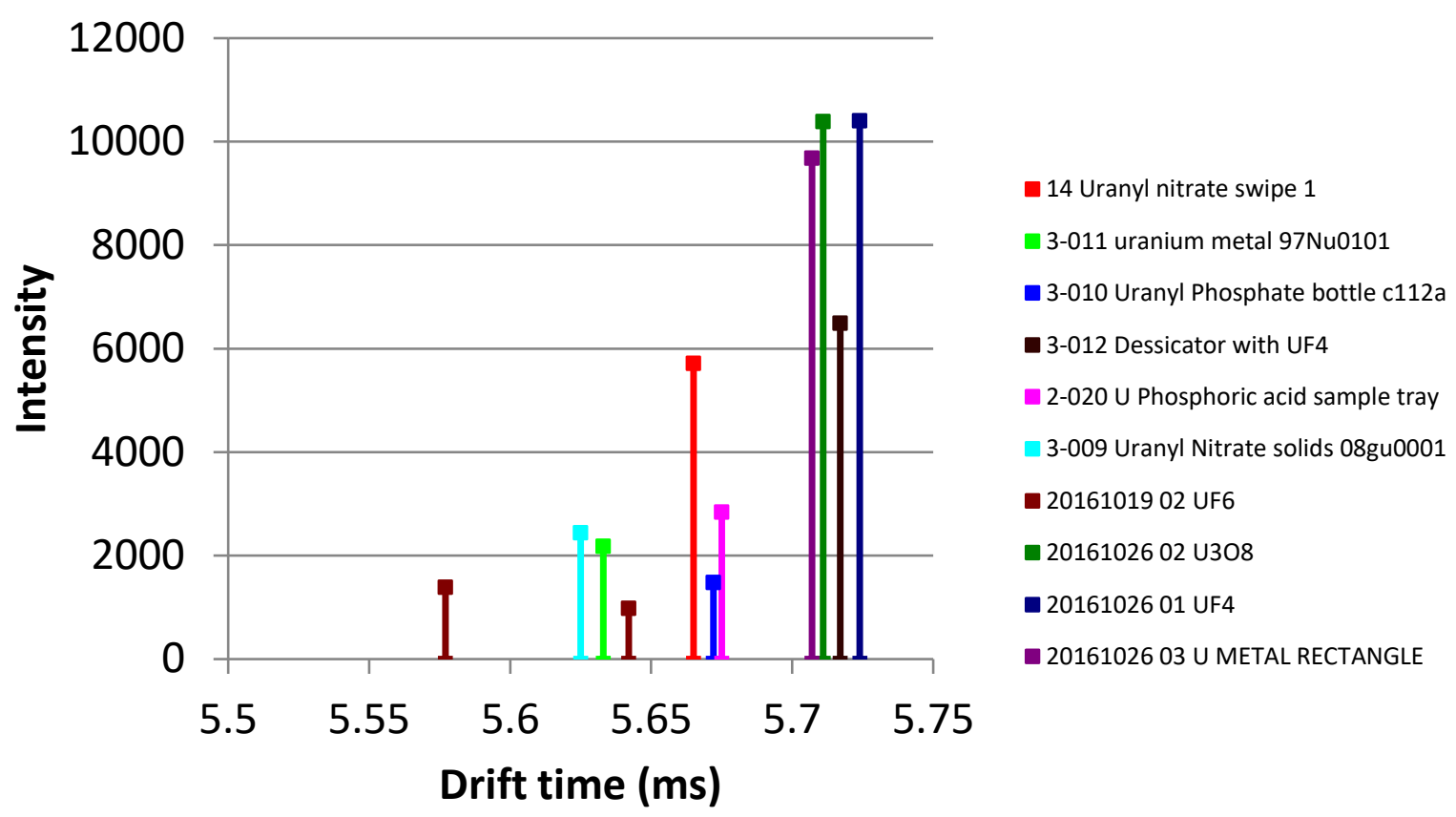

Figure 3 - Comparison (negative long mode only) of swipes suspected of containing multiple uranium compounds. 

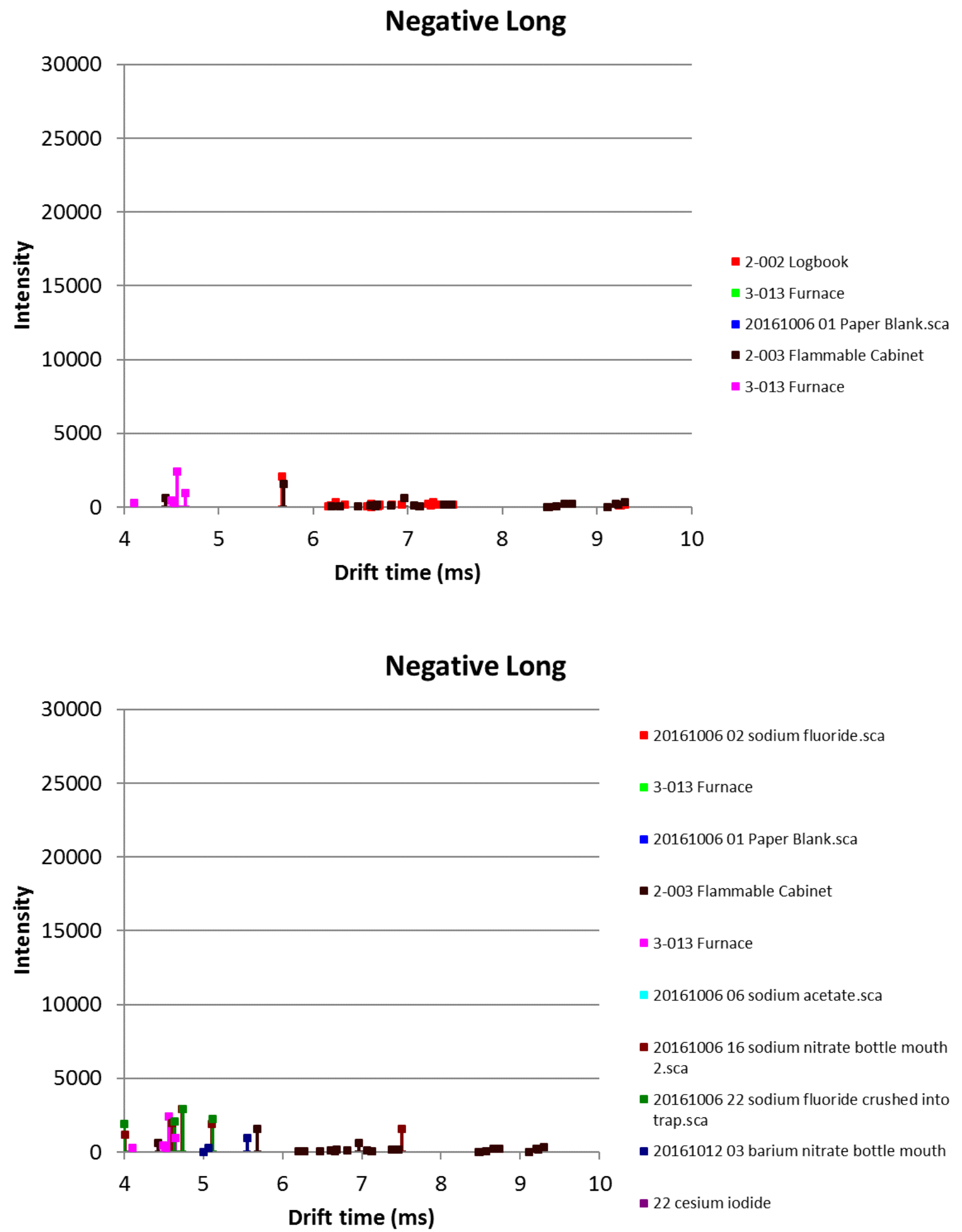

Figure 4 - Comparison in negative long mode of several non-radiological materials and areas not known to house uranium bearing materials. 


\subsection{URANIUM SIGNATURE}

The initial analysis showed a clustering in the negative long/short spectra and therefore, all analyses going forward will focus on those plasmagrams. Once the presumptive uranium signal had been identified, the results were reprocessed by sample origin with 4 different callouts observed: blanks (green), positive uranium samples (red), field test samples (pink), and other chemicals (blue). This analysis was focused on the $5.75 \mathrm{~ms}$ peak in the Negative Long plasmagram. The goal of this was to verify, en masse, that samples that were exposed to uranium, or potentially exposed, included the 5.75 peak while blanks and other chemicals did not.

As shown in Figure 5 and Figure 6, there is a large cluster of signals between 5.5 and $5.8 \mathrm{~ms}$. All positive uranium samples (38 samples, from FY16) have a peak in this region and can be seen in these figures; in addition, all but two of the 50 field test samples show some peak activity. By selecting only those with responses above 2000 counts ( $10 \%$ of the max peak), 33 uranium standards remain while only 22 of the field test points remained. This indicates that while many of the field test samples showed some activity, about half are lowlevel signals that might not be indicative of uranium. Some additional testing in completely radiologically clean locations needs to be done to rule out other chemicals. While the number of positive uranium signals seems high, the facility processed large amounts of uranium in the surveyed laboratories for many years (though the levels are below radiological release limits).

\section{Negative Long}

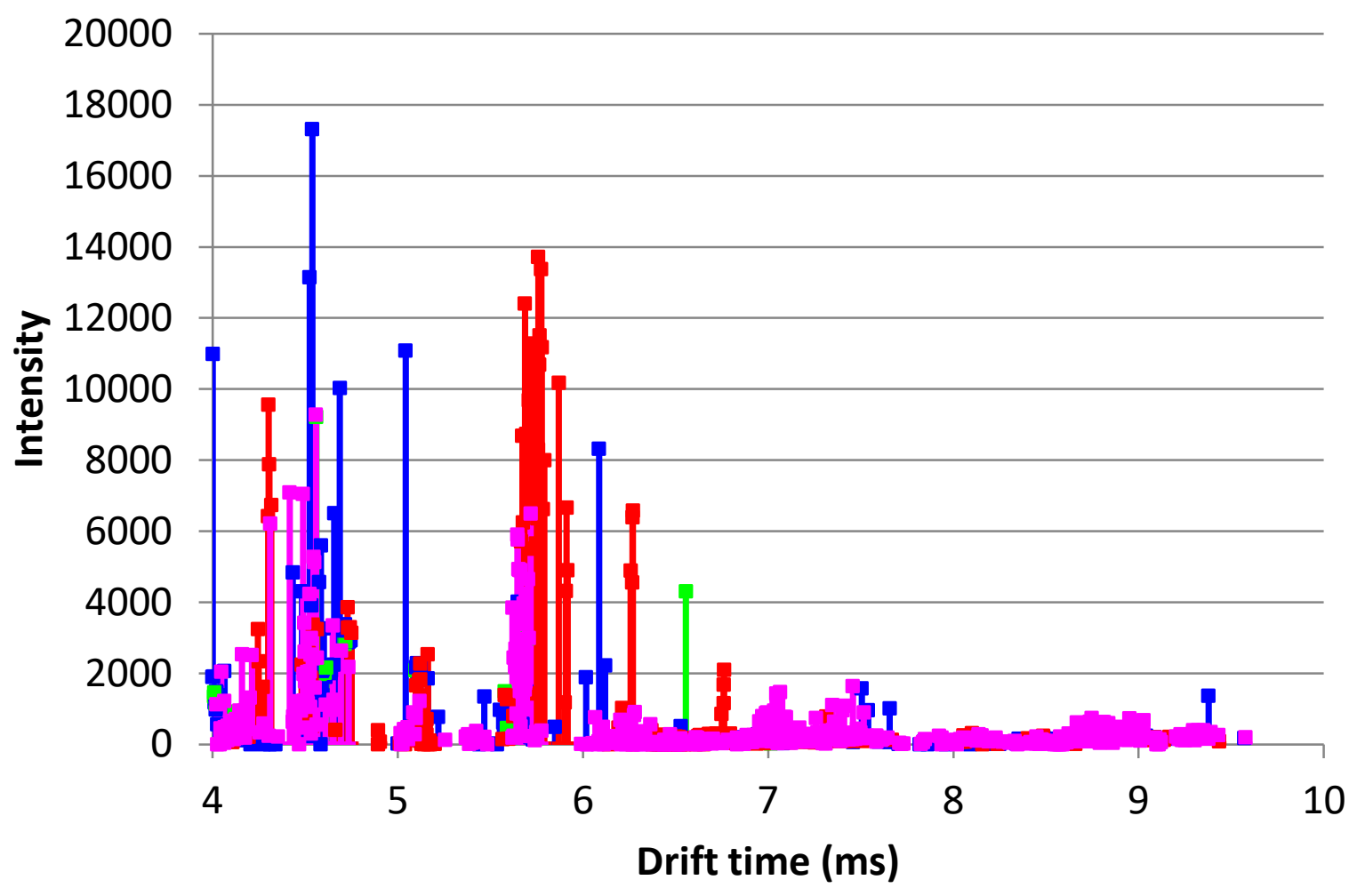

Figure 5 - Color-coded data from FY16/17. Green are blanks; blue represents non-nuclear samples; red are uranium bearing samples; pink are field test samples. 


\section{Negative Long}

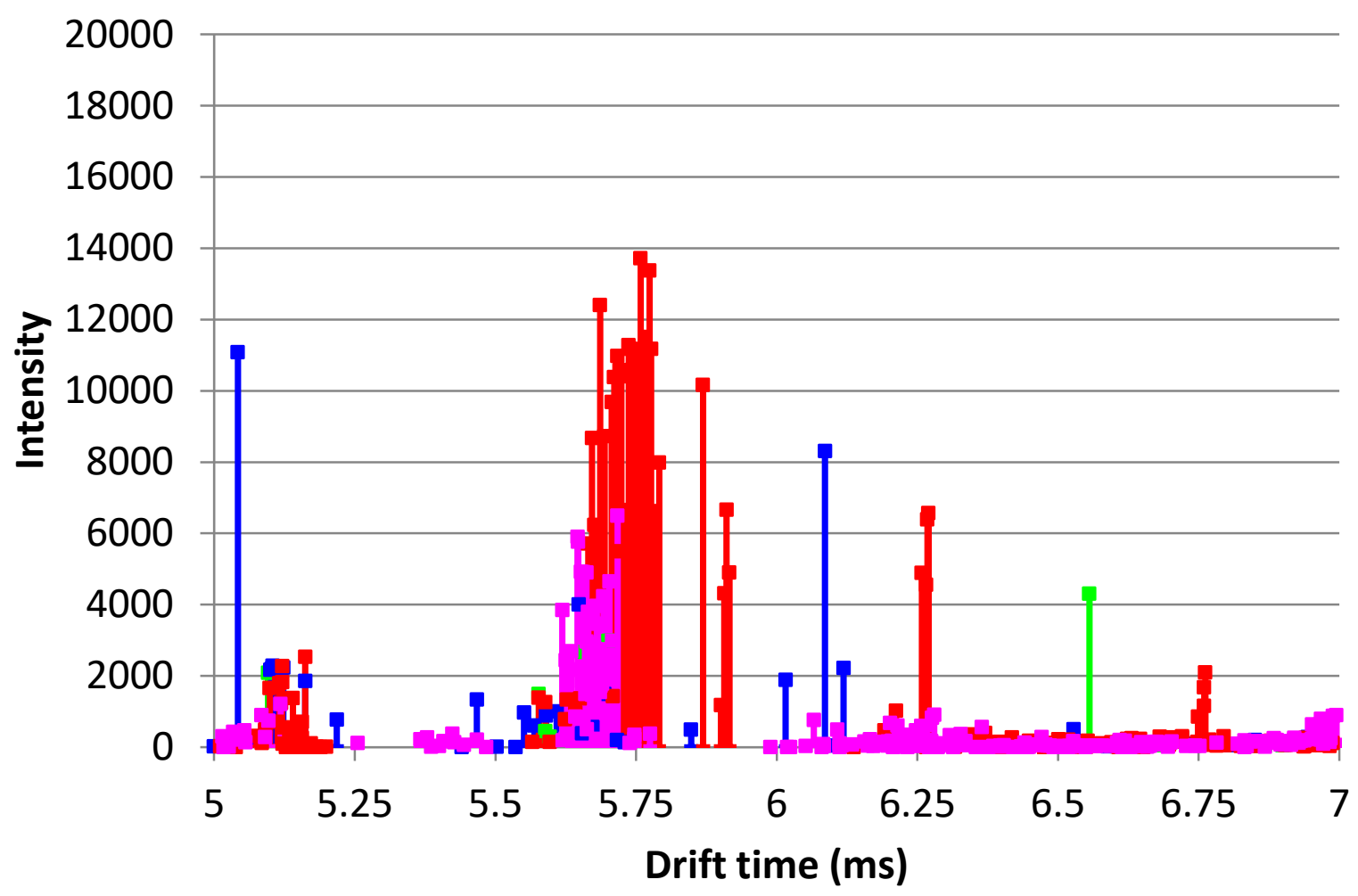

Figure 6 - Color-coded data around the 5.7 ms Peak. Green are blanks; blue represents non-nuclear samples; red are uranium bearing samples; pink are field test samples.

While all of the uranium samples had a peak in the specified range, the high intensity peaks are clustered around 5.75 ms. There are a few peaks in the specified range from blank or other chemicals, though only two blanks and one chemical (barium nitrate) are above the 2000 count discriminator. These samples, as shown Figure 7, are also downshifted to between 5.65 and 5.7. There is a differentiation between the uranium and field test samples, though they all fall within the same larger peak.

There are a few possible explanations for this behavior. One possible explanation is that there are two closely related peaks that are difficult to resolve given the peak resolution of the system. In this case, some of the field test samples may be considered to have positive uranium signatures. A second hypothesis is that the signal is not exceptionally stable and drifts over a $\pm 1.5 \mathrm{~ms}$ range. This is less likely due to the tight clustering in the uranium and field test data; an unstable signal would be more distributed throughout the range. However, both clusters show some structure which leads to a third explanation: the time the samples were collected. The uranium, blank, and other chemical points (red, green, blue) were collected in FY16 while the field test (pink) points were collected in FY17. It is possible that a small shift in response to the uranium signal occurred in the intervening months resulting in a downshift of the drift time. This scenario would indicate that the IMS signal may not be stable and would require a periodic recalibration, which is not unreasonable. The amount of uranium signals detected in 
the facility is not unreasonable given the history of the facility. This final hypothesis is somewhat undercut by the fact that the system passed its calibration checks every day by correctly identifying the narcotic and explosive exemplars; more information on how the instrument passes calibration checks may be required.

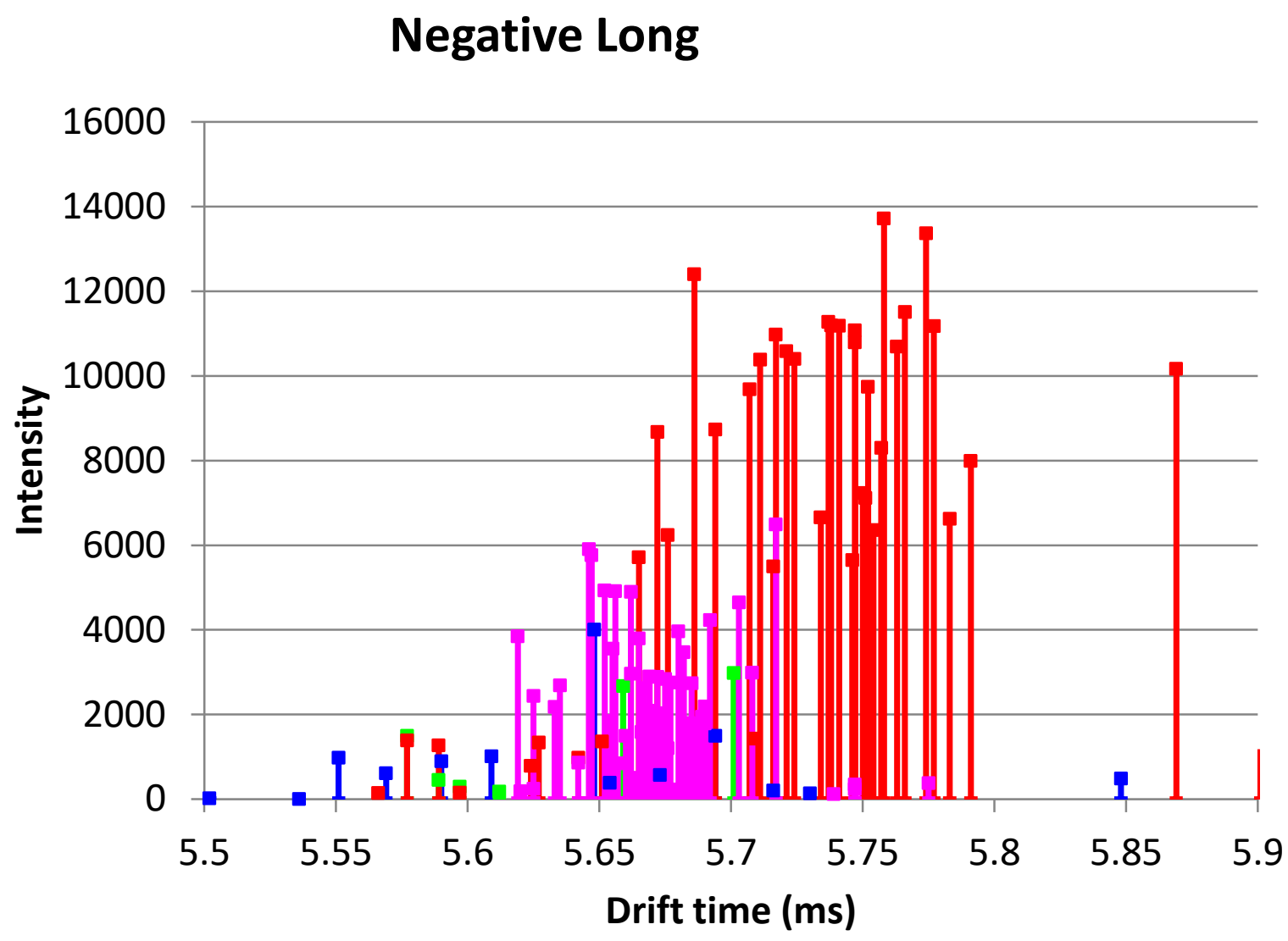

Figure 7 - Overlap of uranium and field test samples. Between 5.6 and $5.8 \mathrm{~ms}$, all uranium bearing or suspect uranium bearing samples had a peak in this range.

\subsection{INDEPENDENT CONFIRMATION}

Samples were taken from many locations within Building 350 for particle analysis and total uranium measurements. These samples will be analyzed by an external collaborator and results may be made available for retroactive analysis. In the event that useful information is obtained, an addendum to this report will be issued. 


\section{CONCLUSIONS, LESSONS LEARNED AND FUTURE WORK}

\subsection{Field Test Specific Observations}

Vendor information needs to be supplied for all items that will be used in the test to ensure that adequate and prompt reach back support is available to the researchers.

\subsection{Field Test RESUlts}

Current results indicate the likely detection of a uranium signal in a complex background. While the results are encouraging, the actual level of detection has not been quantified with external analyses and the signal is still semi-quantitative. With additional work and involvement with the manufacturer, a definitive limit of detection can be established.

\subsection{Potential Safeguards Uses}

The obvious use for this technology is to identify those areas within a facility that are likely to have uranium contamination. These areas would then be subject to a more traditional ESS for analysis by Agency scientists. The low detection limit of the instrument would allow for more focused samples to be taken and reduce the total number of EV ID that need to be processed. They would also allow high priority samples to be processed first by identifying which areas were likely to have usable material deposited on them.

A secondary use for safeguards is a primary use of the technology in its normal role: explosives detection. For states that exist under an AP agreement, there are several research activities that would be indicative of a weaponization process being developed including work with high explosives in laboratories or by personnel connected with the nuclear program. IMS systems were originally pushed into use by DHS to detect low concentration levels of explosives and narcotics. 


\section{APPENDIX A - SAMPLING PROCEDURE}

\subsection{SAMPLING}

1. Identify surface to be analyzed

2. Record area description and issue sample number

3. Document area

a. Photograph area using a ruler or visual aide (including image post processing) to indicate area of sample

i. Save photo with sample number

b. Identify any substances in the area

i. Collect information on material identities, compositions, chemical forms, Certificates of analysis, etc.

ii. Save as entry in sample log file

4. Swipe the surface to be analyzed with a sample trap

5. Perform any additional swipes of surface (HP or external)

6. Give IMS trap to HP Tech for alpha counting

a. Record pre-IMS alpha level

7. Present the trap to the IMS

8. Give trap to HP Tech for alpha counting

a. Record post-IMS alpha level if activity was detected in 6.a.

9. Discard the trap appropriately

\subsection{Data Logging}

1. Use IMS software to export peak data for all four transit modes (Positive and Negative Short/Long) to a spreadsheet

a. Move file to external memory and transfer to a computer for storage

b. Back up data as soon as practical

2. Combine spreadsheet files, pictures, metadata in one location (likely a workbook)

3. Compute the total amount of alpha emitting activity deposited in the IMS (from Sampling: 6.a. and 8.a.)

a. Add total deposited uranium to the running log 


\section{APPENDIX B - PHOTOS AND MAPS}

For all samples in series 2, a photograph was taken of the swipe area and marked with a blue line to indicate the actual path of the swipe; series 3 swipes were swipes of areas previously photographed. Maps are included at the end to indicate where in the laboratory the swipe was taken. IMS locations are denoted by a sample ID and arrow; EV smear samples are denoted by a red/orange rectangles, sample IDs and arrows. Please see Table 1 for additional information. Only images for C110, C126, and C138 are provided. The samples taken in C238, C250 were not photographed.
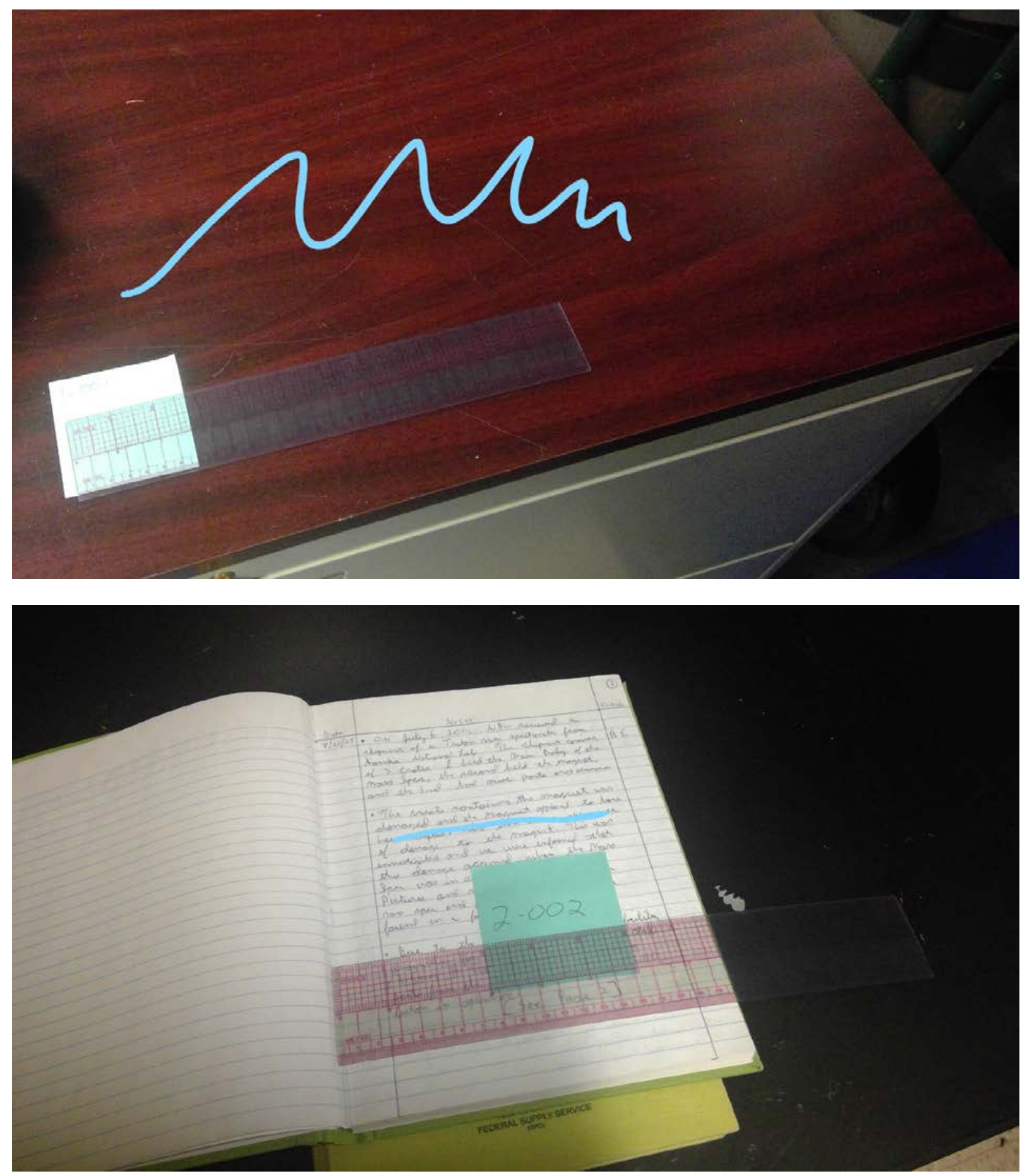

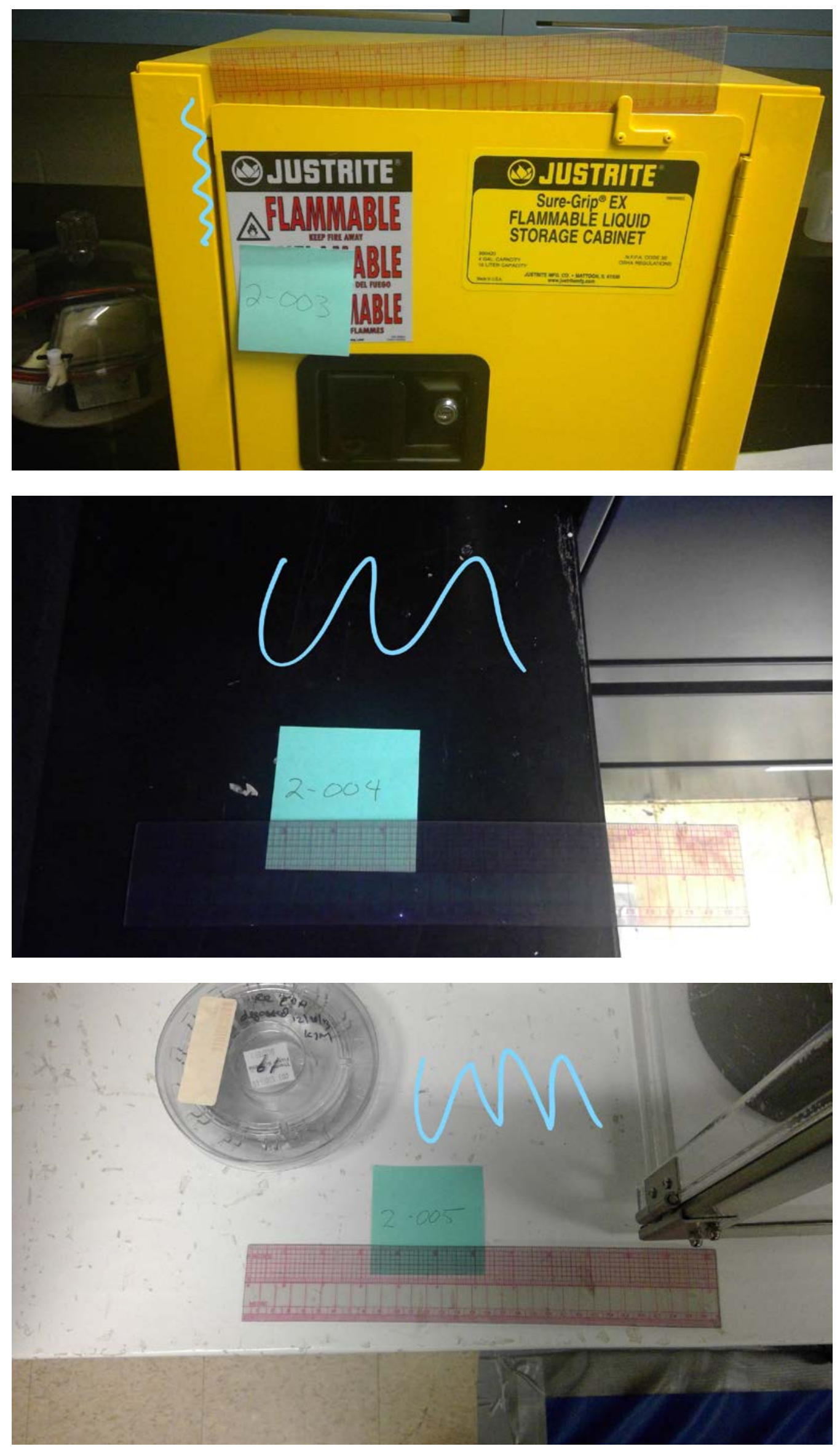

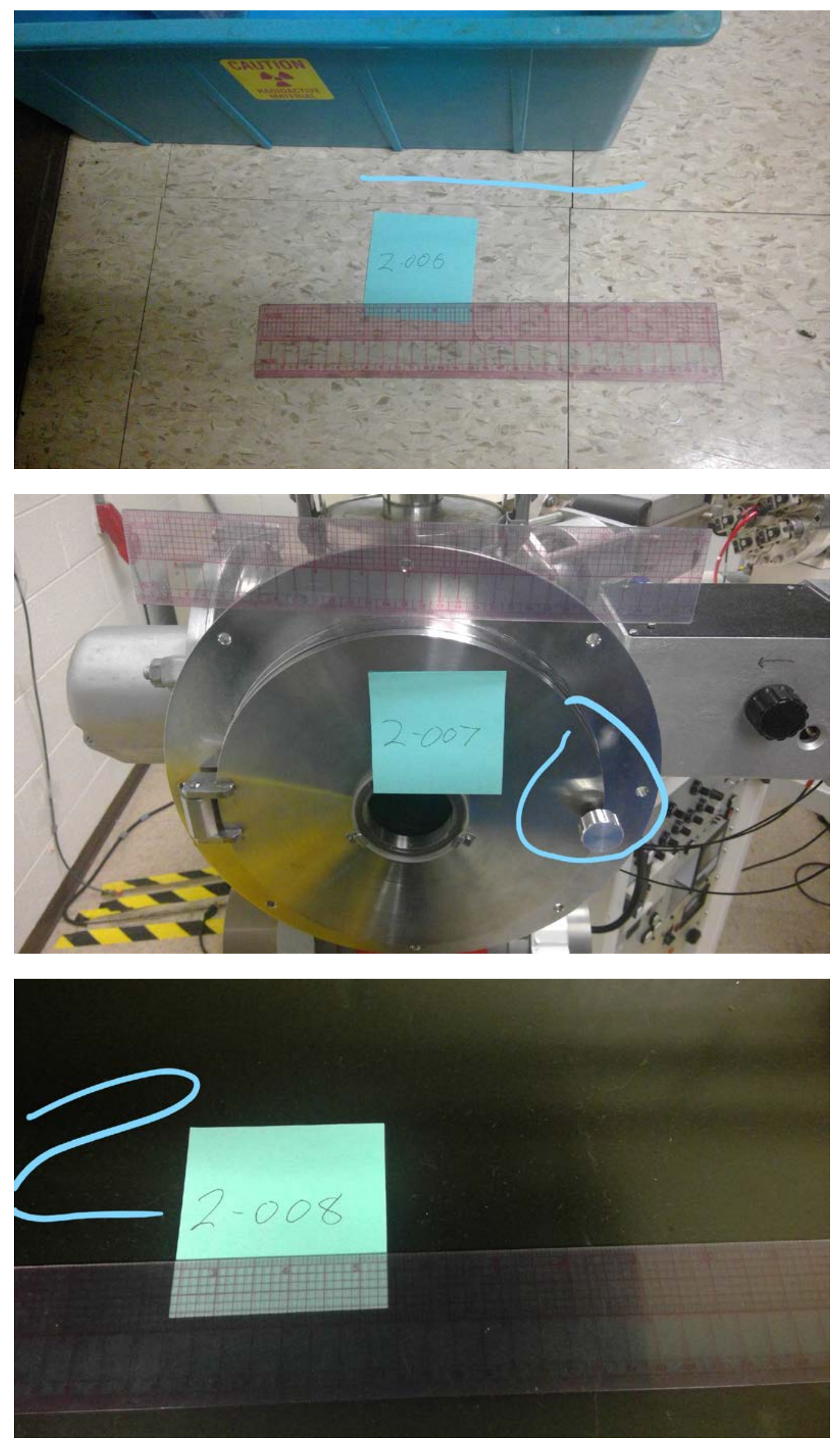

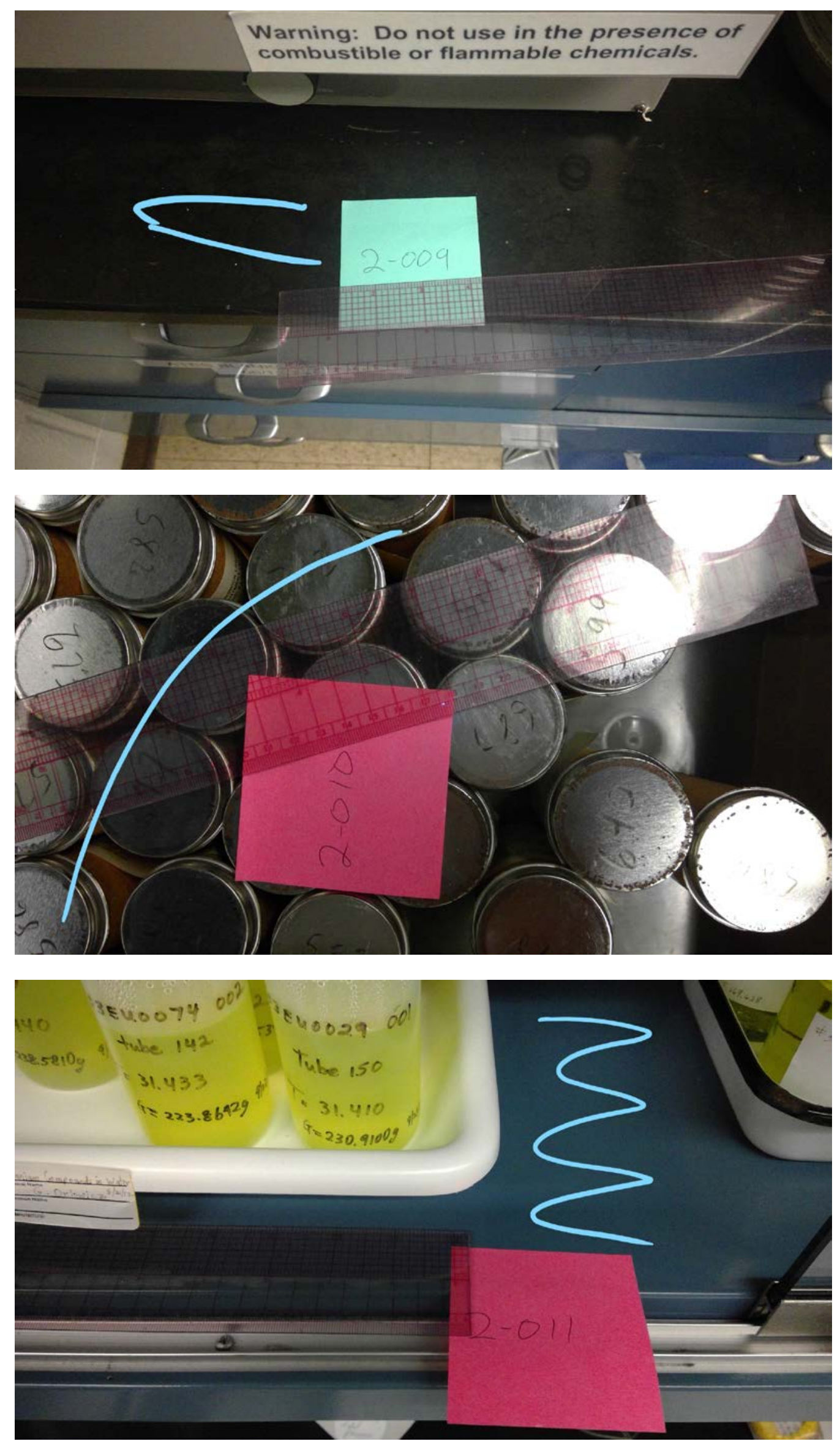

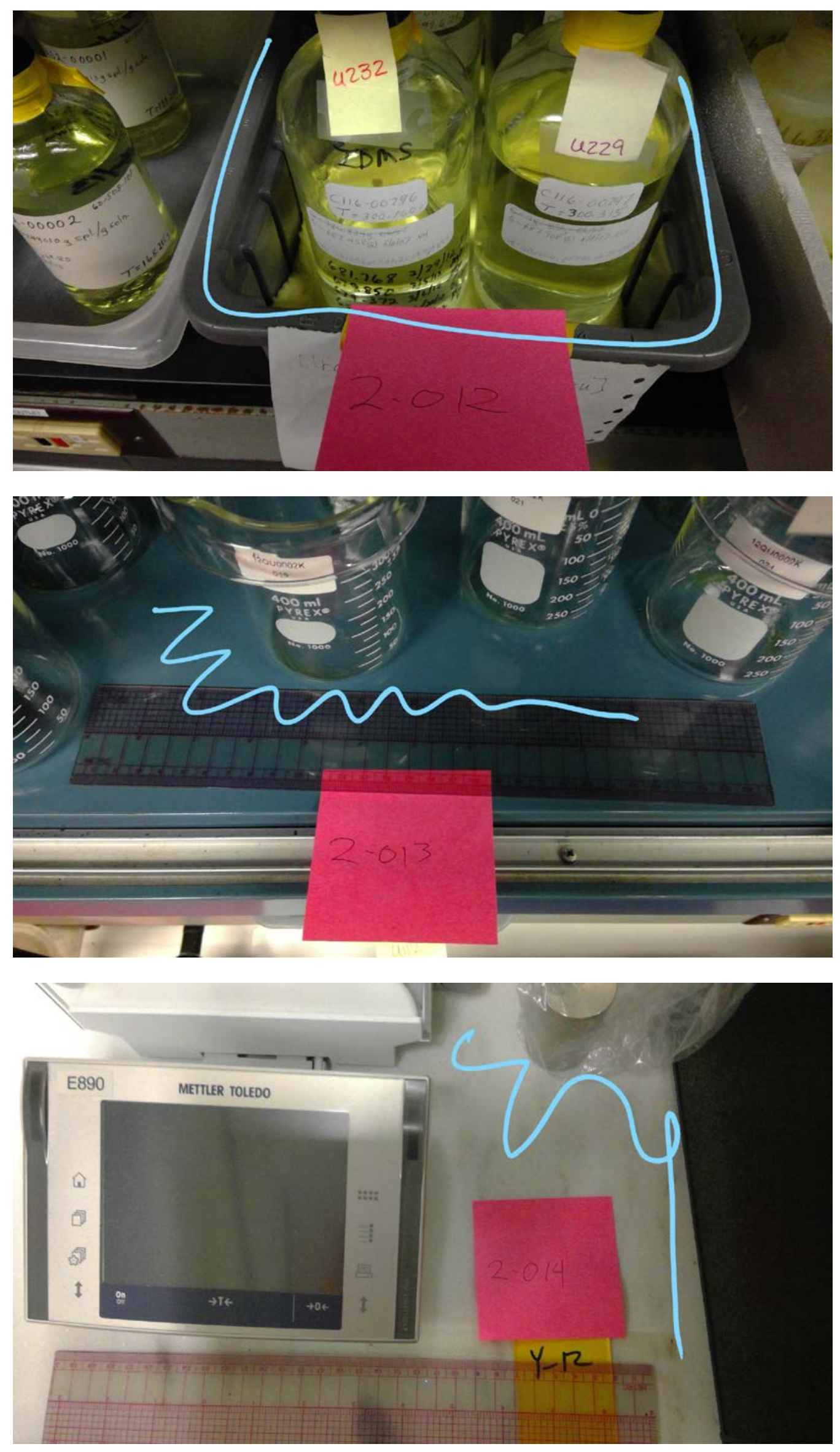

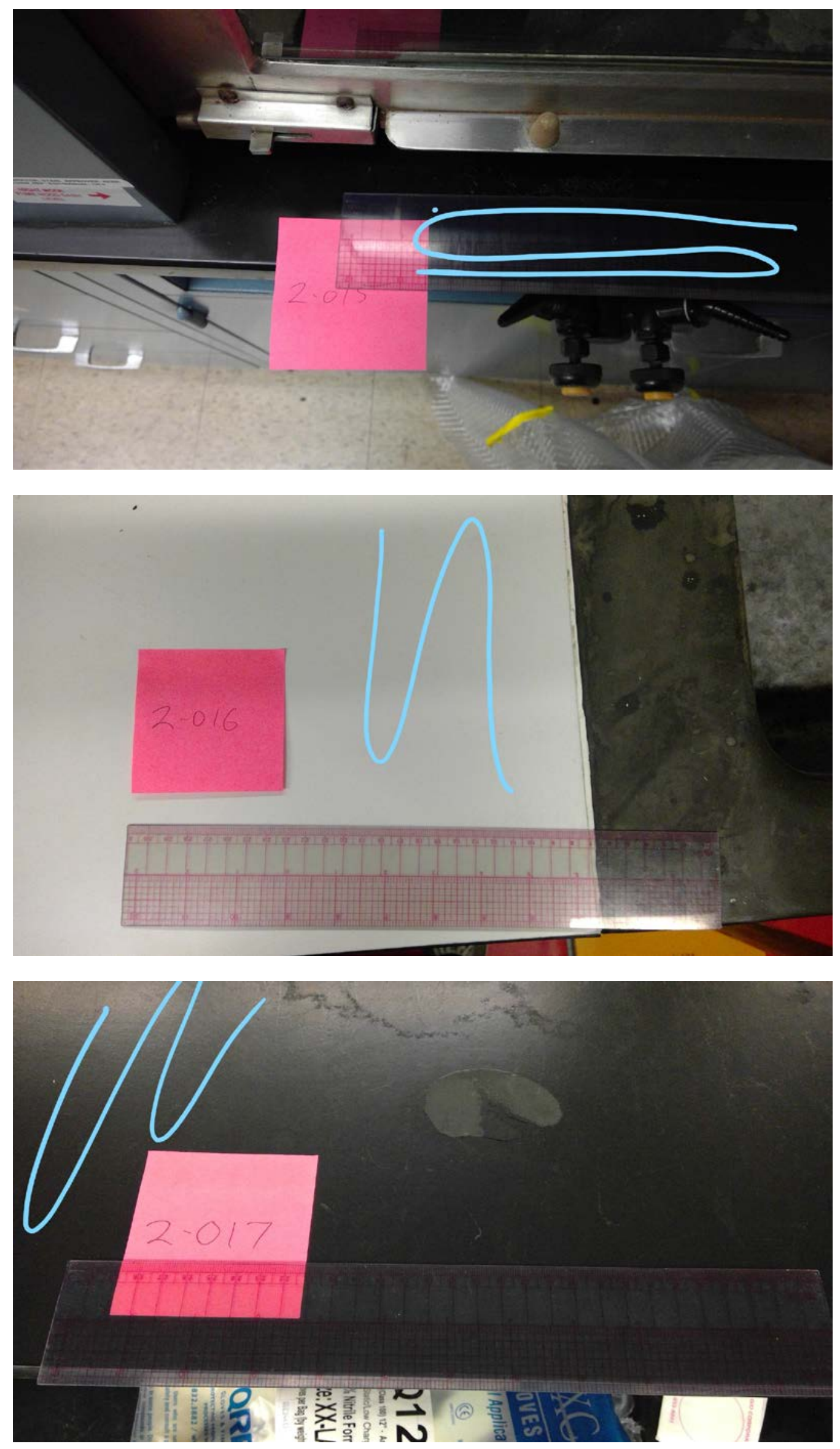

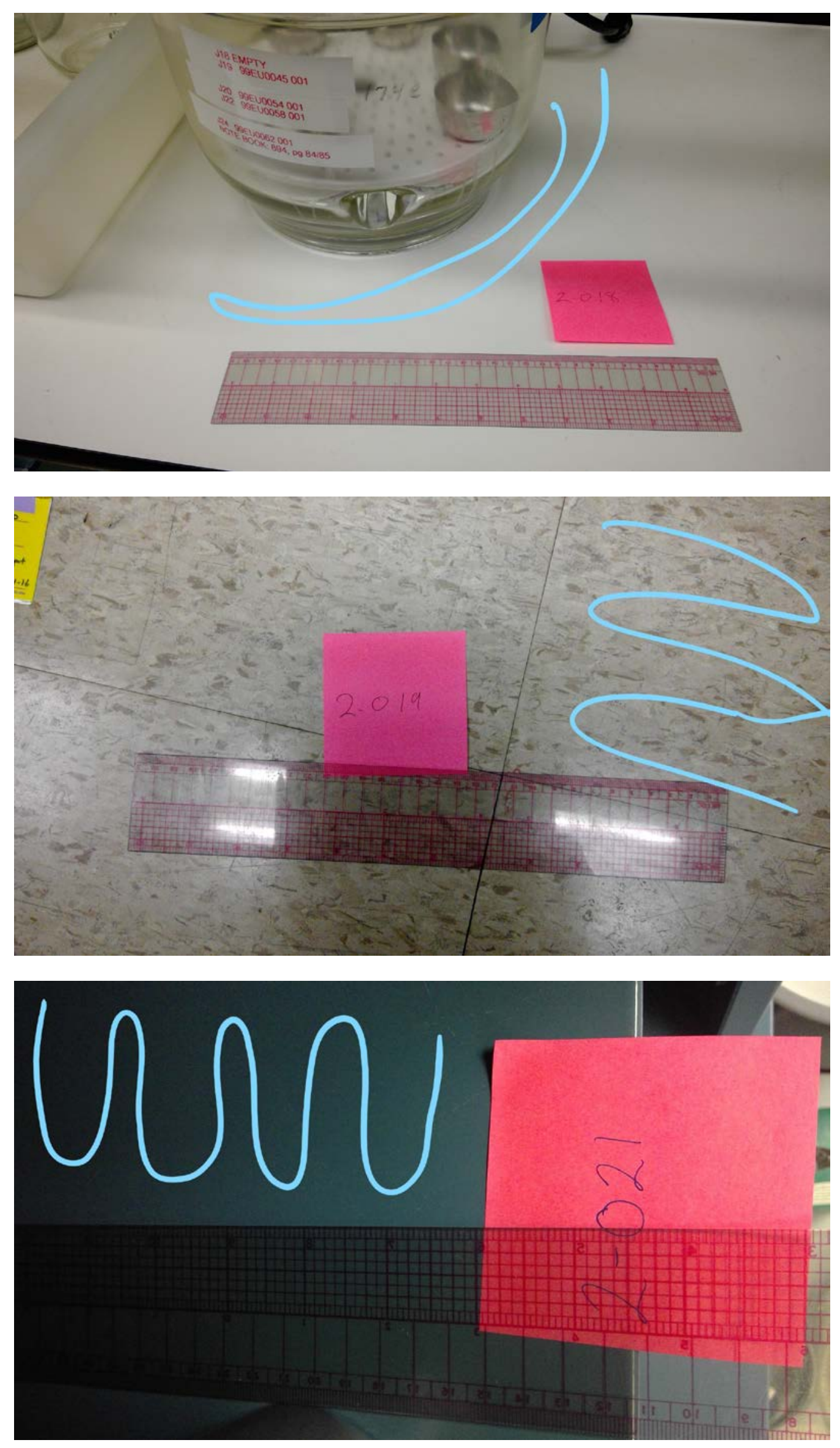

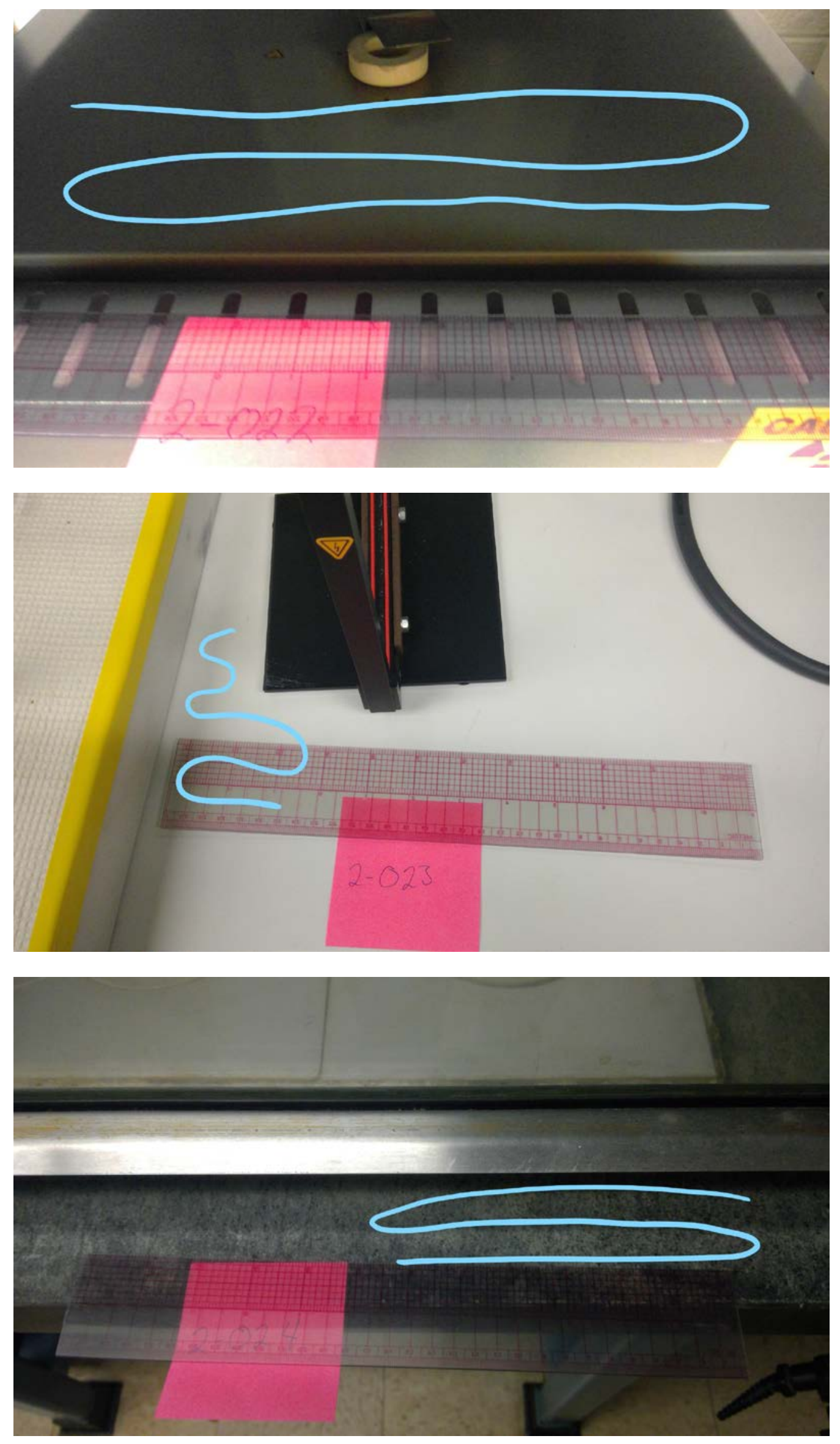

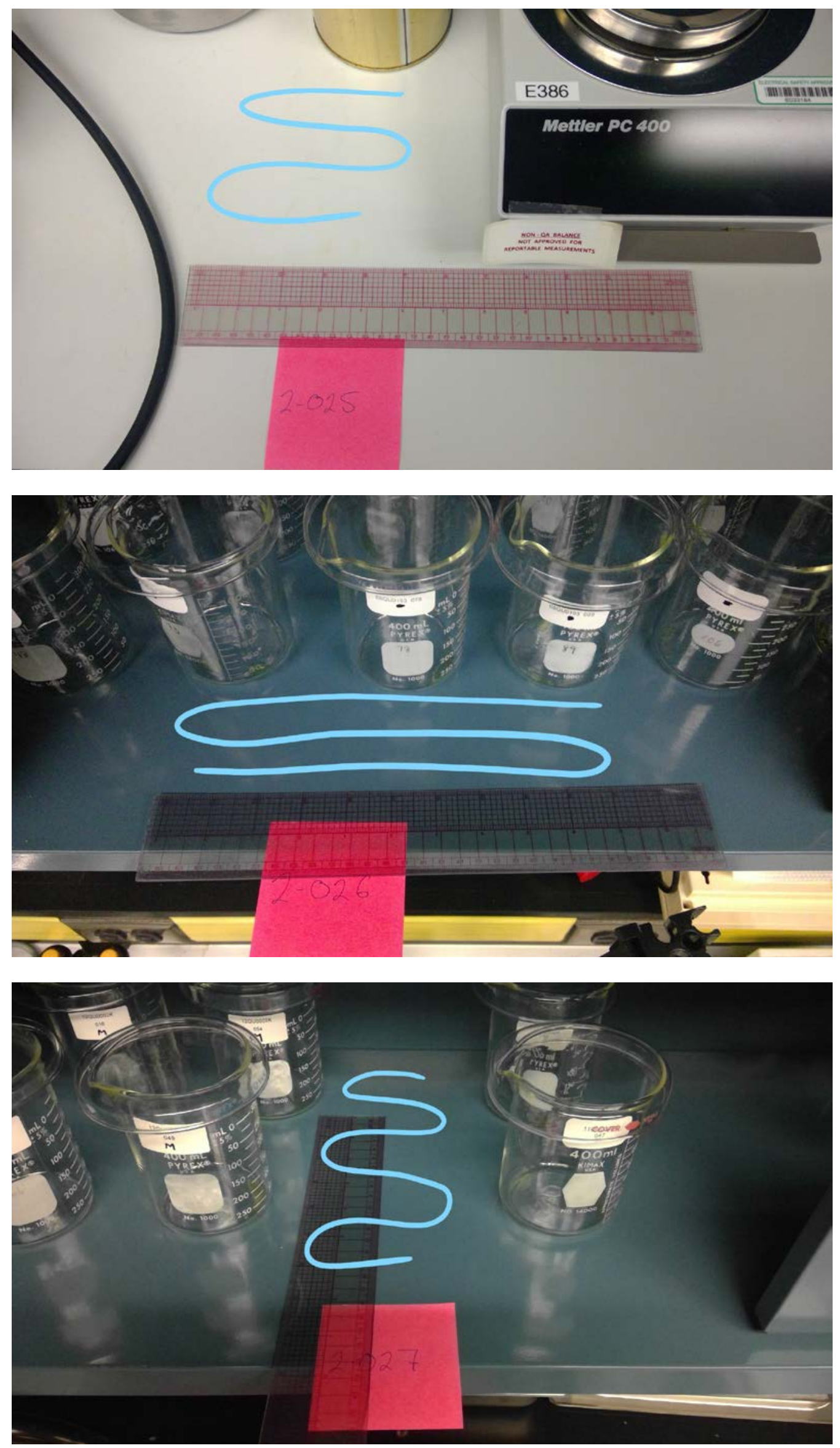

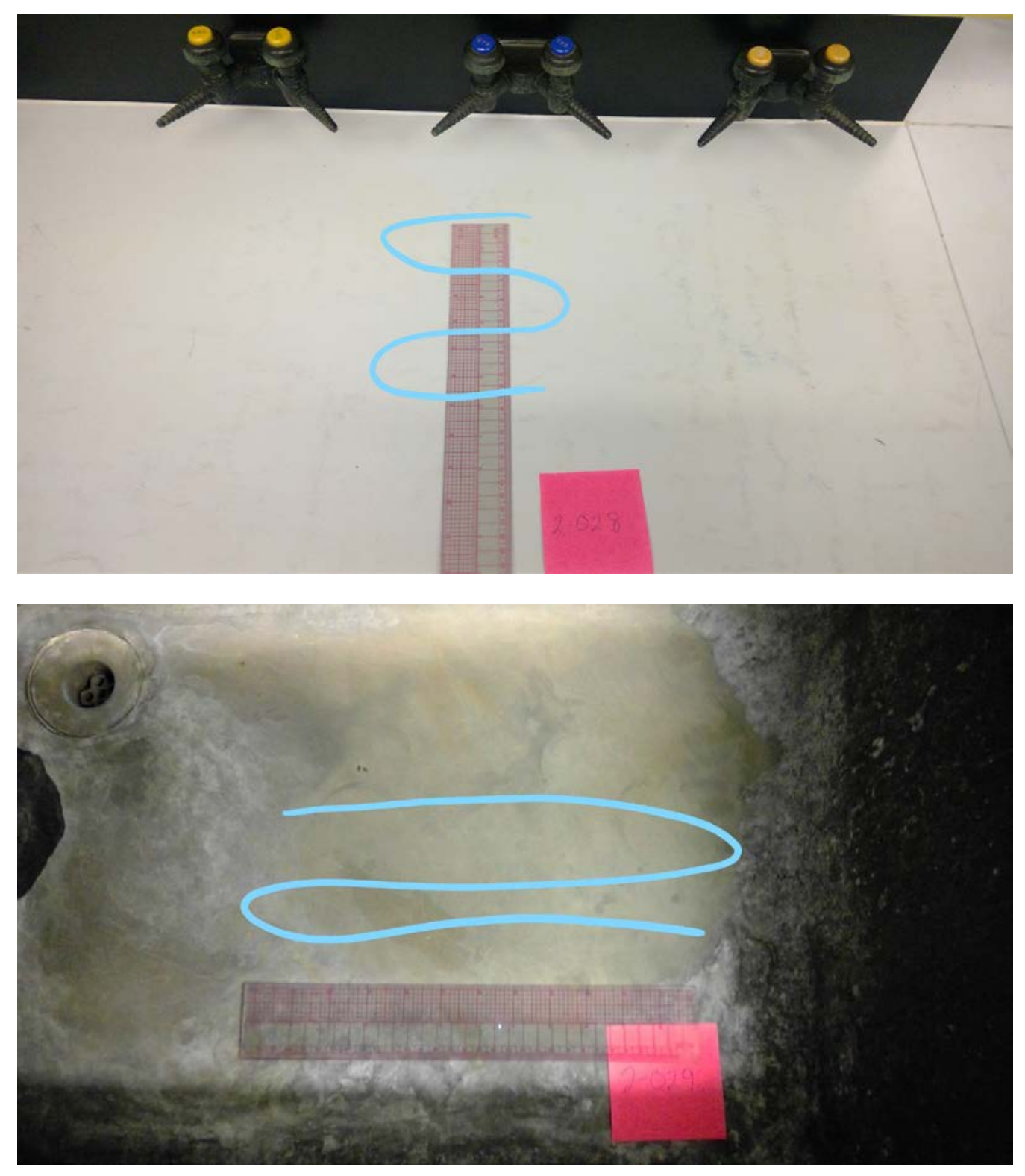

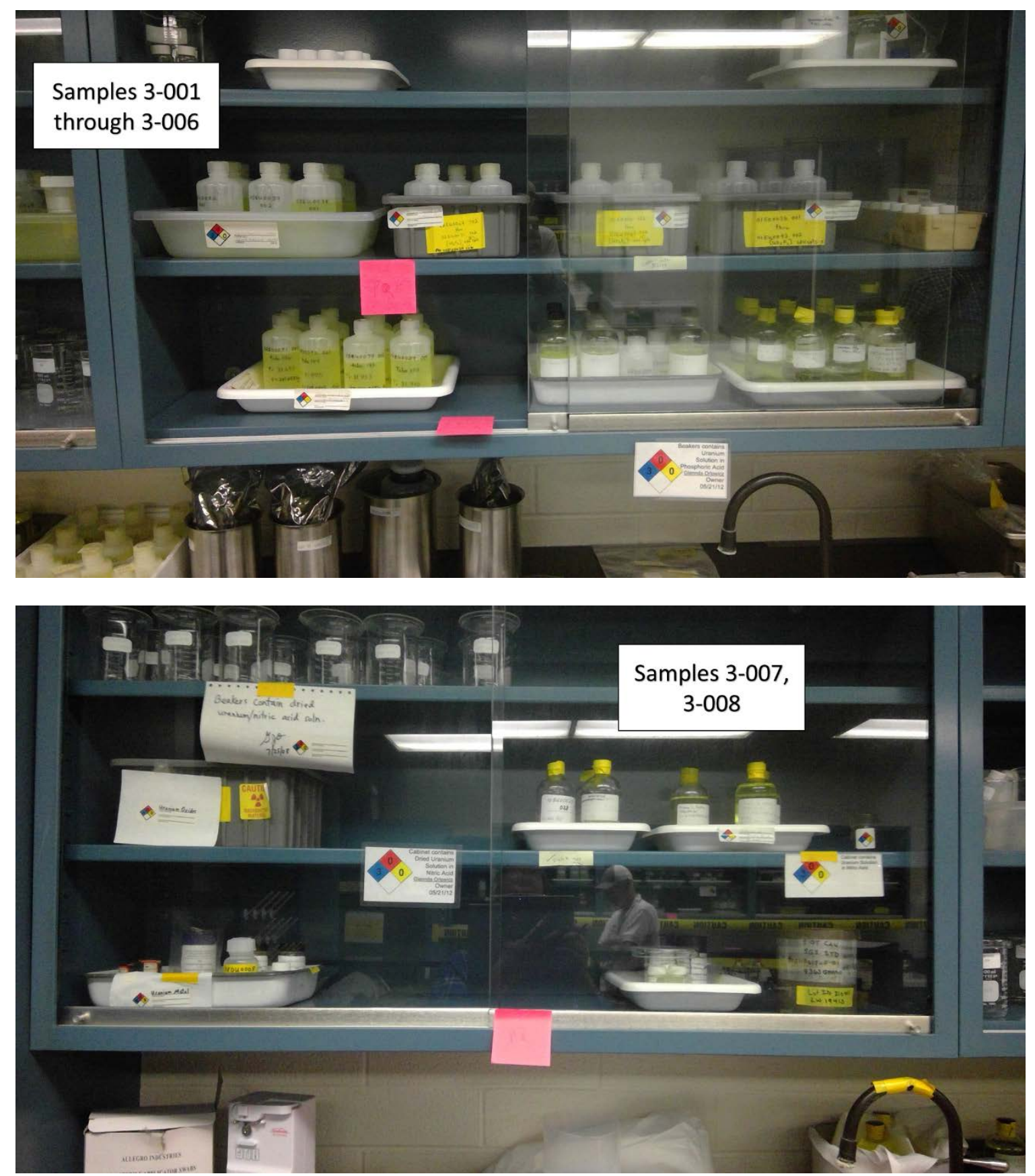


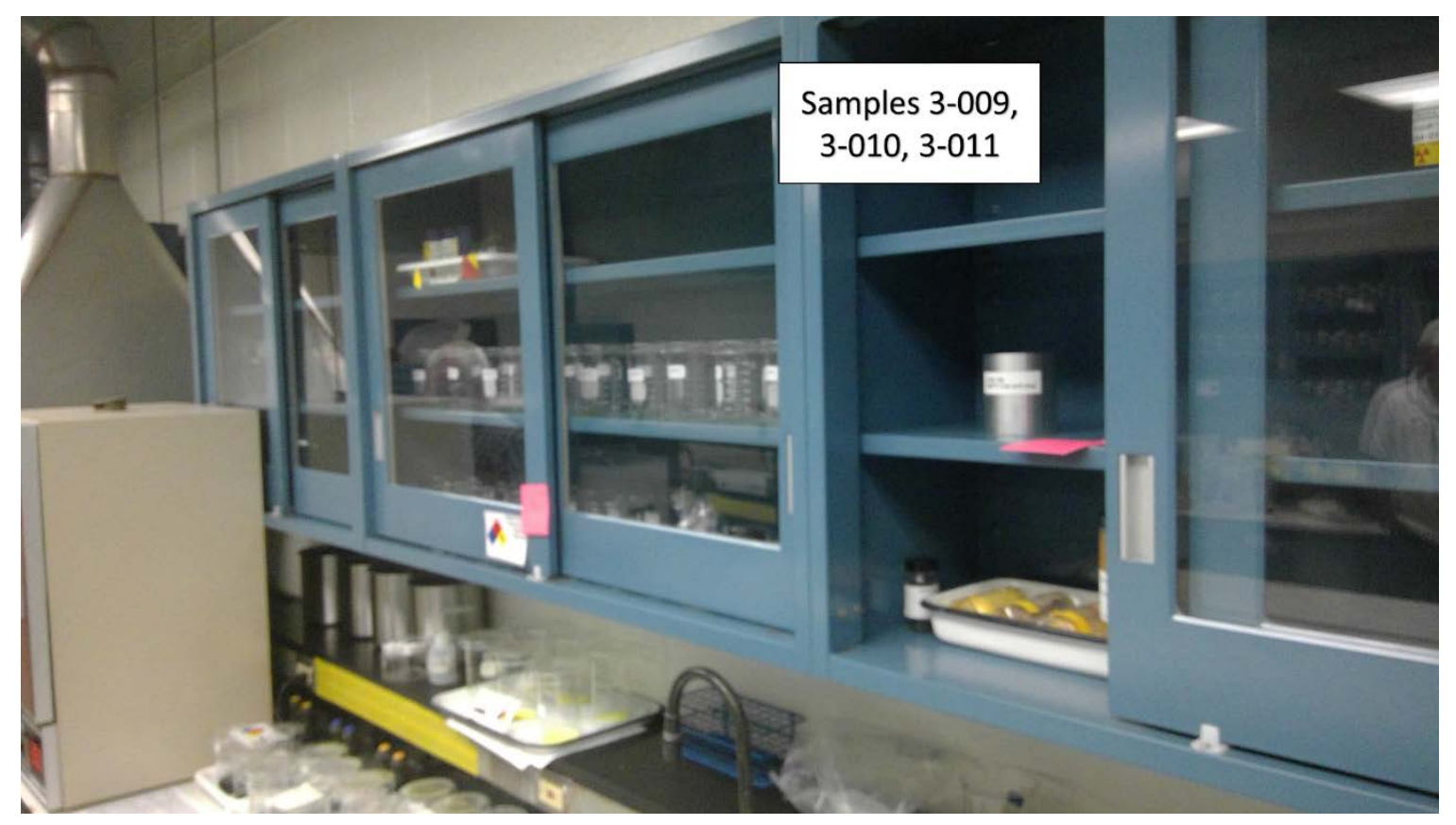




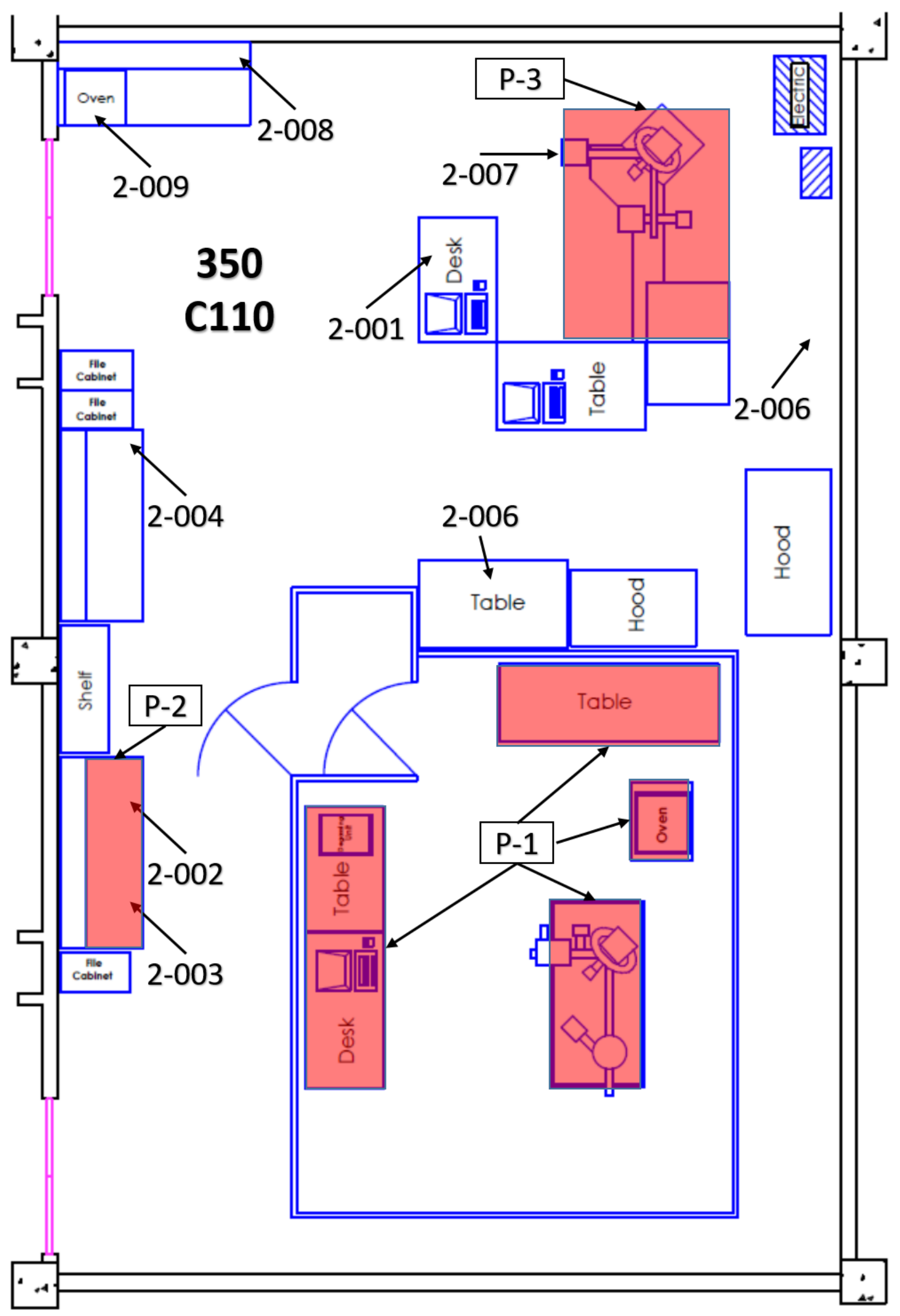




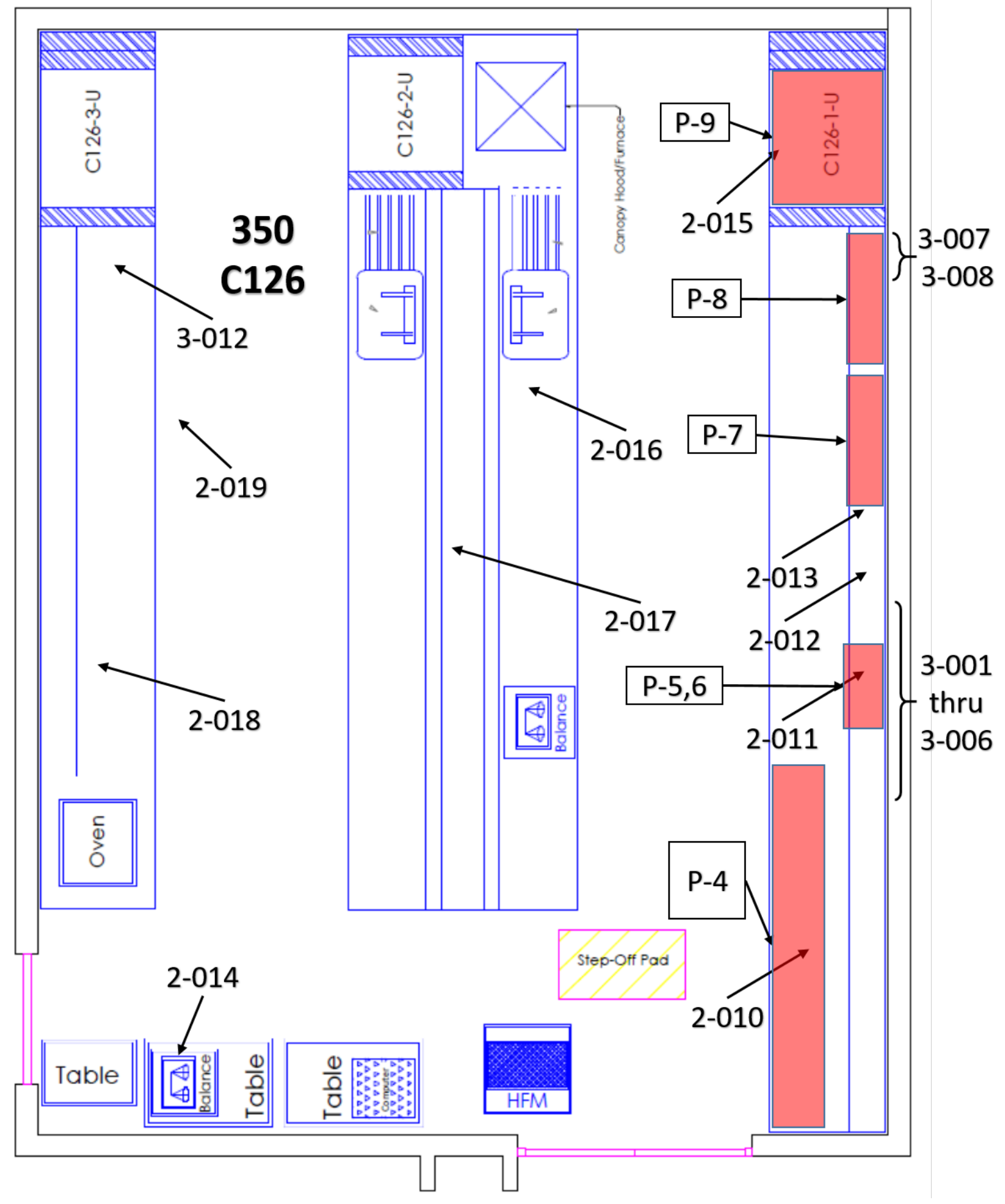




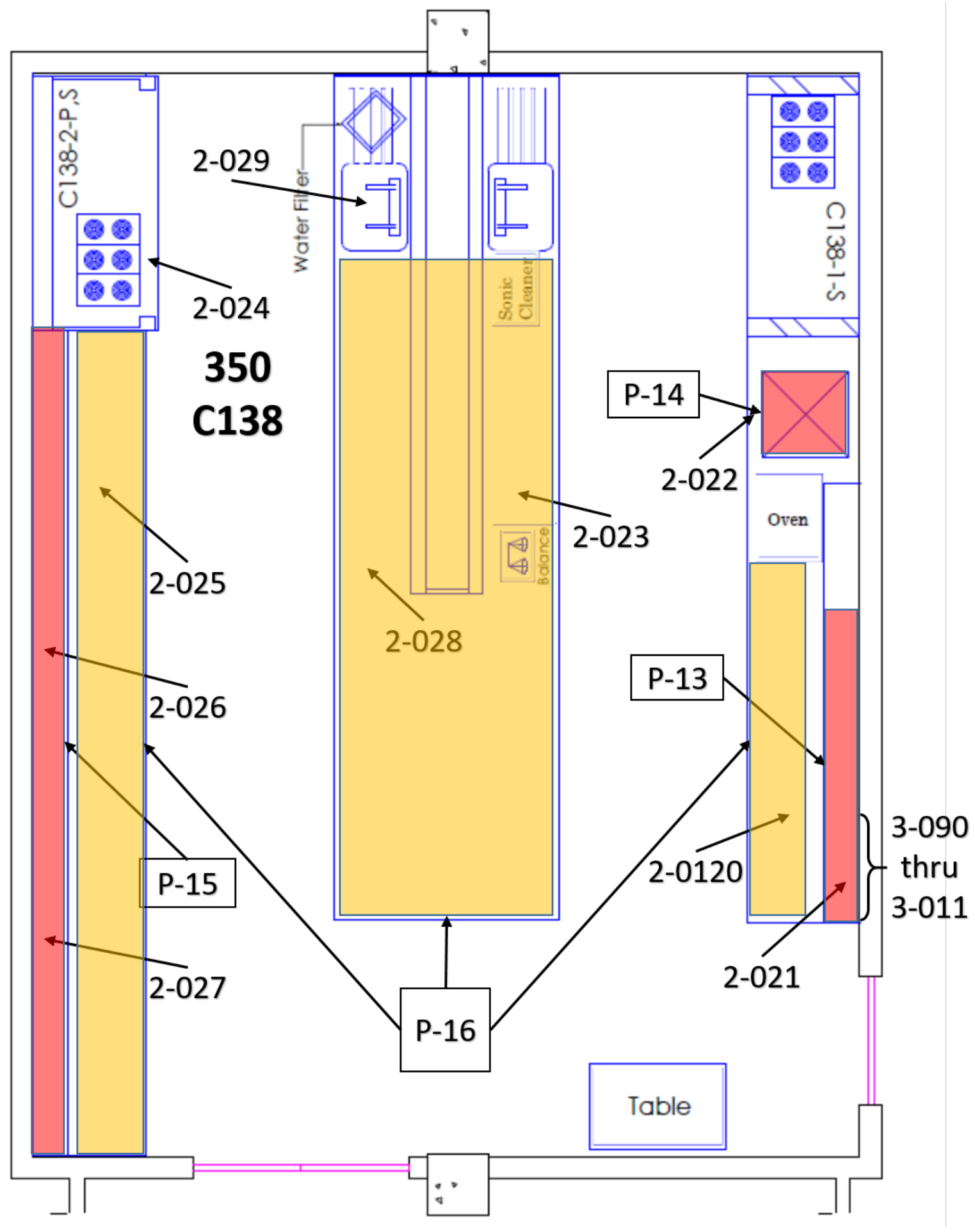




\section{Argonne}

Nuclear Engineering Division

Argonne National Laboratory

9700 South Cass Avenue, Bldg. 205

Argonne, IL 60439

www.anl.gov

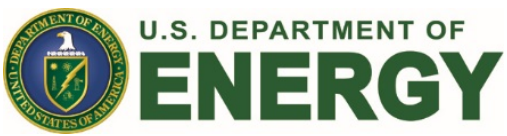

Argonne National Laboratory is a U.S. Department of Energy laboratory managed by UChicago Argonne, LLC 